Article

\title{
Exploring the Development of Research, Technology and Business of Machine Tool Domain in New-Generation Information Technology Environment Based on Machine Learning
}

\author{
Jihong Chen ${ }^{1}$, Kai Zhang ${ }^{1}$, Yuan Zhou ${ }^{2, *} \mathbb{D}$, Yufei Liu ${ }^{3}$, Lingfeng Li $^{1}$, Zheng Chen ${ }^{1}$ and Li Yin ${ }^{1}$ \\ 1 National Numerical Control Systems Engineering Research Center, School of Mechanical Science \\ and Engineering, Huazhong University of Science and Technology, Wuhan 430074, China; \\ chen_jihong@189.cn (J.C.); zksyneu@hust.edu.cn (K.Z.); li_lingfeng@hust.edu.cn (L.L.); \\ chen_zheng625@163.com (Z.C.); yinliforce@hotmail.com (L.Y.) \\ 2 School of Public Policy and Management, Tsinghua University, Beijing 100084, China \\ 3 The CAE Center for Strategic Studies, Chinese Academy of Engineering, Beijing 100088, China; liuyf@cae.cn \\ * Correspondence: zhou_yuan@mail.tsinghua.edu.cn
}

Received: 15 May 2019; Accepted: 11 June 2019; Published: 15 June 2019

check for updates

\begin{abstract}
The combination of new-generation information technology and manufacturing technology has had in a significant and profound impact on the future development paradigm of manufacturing. Machine tools are the basis of virtually everything that is manufactured in the industry, exploring the development of the machine tool domain is of considerable significance to identify the opportunity to develop manufacturing industry and promote the sustainable development of manufacturing in the current tightening constraints of resource environment. Although much attention has been paid to development studies of a specific domain in recent years, it is challenging to conduct a multidimensional study related to the development status of the machine tool domain using existing methods. To solve this challenge, we propose an integrating framework combining topic models, bibliometric, trend analysis and patent analysis to mine multi-source literature within the machine tool domain, including papers, funds, patents, and news. Specifically, papers and funds provided two different perspectives to explore the development status in the research of machine tools. Furthermore, the technology development of machine tools was investigated through patents analysis. Finally, news related to the machine tool industry in recent years was analyzed to examine business focuses on machine tools. The integration of above various analytical methods and multi-dimensional mining of literature enabled analyzing the development of the machine tool domain systematically from multi-perspectives that include research, technology development and industry to provide inspirations about the implications of sustainable development of this domain. The conclusions obtained in this paper is beneficial to different communities of machine tools, in terms of determining the research directions for researchers, identifying industry opportunities for corporations and developing reasonable industry policy for policy makers.
\end{abstract}

Keywords: development analysis; machine tool; multi-source; machine learning; topic model

\section{Introduction}

The explosive growth of the new-generation information technology and the deep integration with manufacturing technology have formed the main driving forces of the new round industrial revolution, which is triggering significant and profound changes in the technical manufacturing systems, development paths and industry modes [1-3]. The machine tool is the ubiquitous instrument 
in the manufacturing industry and virtually everything in the industry is manufactured using it [4]. As machine tool plays a unique and critical role in the industry, machine tool technology is bound to become the essential part to the change of manufacturing in the condition of new-generation information technology and thus support the sustainable development of manufacturing further [5]. As a symbol of manufacturing paradigm change, exploring the development of the machine tool is of considerable significance to identify and grasp the opportunity to develop the manufacturing industry for a variety of communities. Moreover, considering the advent of the Fourth Industrial Revolution and the current tightening constraints of resource environment it is also critical that analyze the development of the machine tool domain to provide inspirations about the direction of sustainable development of this domain.

The development of a specific technology domain depends on the synergy of intrinsic characteristics of technology and external factors. Through the analysis, we conclude that the machine tool domain possesses the following two complex characteristics.

(1) Complex inherent heterogeneous nature of machine tool technology. The reason lies in machine tool technology belongs to an interdisciplinary categorization whose technical categories cover various fields, such as mechanics, hydraulics, control, materials, microelectronics and information technology. Complex interactions and effects exist in various related technical fields, presenting complex intrinsic heterogeneity [6].

(2) The dimension complexity of development caused by the deep integration between the new-generation information technology and machine tool technology. The cross-integration of the emerging information technologies and machine tool domain runs through all aspects of research, management, service and other technical activities. As a result, conducting a simple analysis of a certain dimension of technical activities is difficult to clarify the development status in the machine tool field comprehensively [7].

The two complexities summarized above make it a challenging task to explore the development of the machine tool field.

Many researchers have focused on exploring the development trajectory of the machine tool discipline. Raju et al. carried out a qualitative literature study to describe research focuses and current trends on micro electro-discharge machining, including its requirements, performance and applications [8]. In addition, similar literature reviews that were carried out to explore the current states and trends of a specific subcategory of machine tools exist $[9,10]$. The characteristic of these studies is based on the accumulated expert's experience to qualitative review the papers related to a specific sub-technology of machine tools and analyze its development trend. Due to the recent change of the information environment in the machine tool domain, some research aimed at exploring the development of machine tool technology also depended on qualitative analysis [5]. Based on expert domain experience, these works provided valuable insights to some extent for guiding the future development of technology. However, it is difficult to explore a large number of related papers by reading them because of the enormous time and energy required and the difficulties in comprehending topics in heterogeneous areas [11]. The above qualitative analysis method is incapable of keeping up with the rapidly increasing number of papers comprehensively in the whole machine tool discipline. In addition, it is challenging for conventional qualitative review method to tackle the complex inherent heterogeneous of technology. Moreover, the above qualitative works are based solely on the literature review of the papers of specific machine tool technology or the analysis based on expert experience, but failed to conduct multi-dimensional collaborative exploration from various aspects, such as research, technology development and business. As a result, the conclusion obtained from review analysis is easy to generate knowledge solidification and make inferences along the existing technical paradigm, which may lead to the neglect of emerging trends under the new technology development paradigm [12,13].

Scientific literature has been considered as a valuable and rich source of knowledge or a key proxy about technology development, reflecting the current technological focuses in their respective discipline 
and the trend of technology development in both theory and practice $[14,15]$. Bibliometric or the patent analysis has been widely used by many researchers to analyze scientific literature quantitatively, which is regarded as a more systematic, objective, and effective method compared to qualitative literature review approach to explore the changes of specific discipline [16-20]. For example, Ernst analyzed the patent data in the machine tool industry to detect and trace the changes in Computerized Numerical Control (CNC) technology [21]. Attempts to quantitative analysis of the development of the domain by methods, such as bibliometric, can help to alleviate the limitations of objectivity and comprehensiveness of qualitative review method to some extent [22,23]. However, these works ignored the multi-dimensional analysis of multi-source literature related to a specific domain [24]. To solve the above limitation, more attention has been paid to the integration of multi-source data when conducting research on technology development $[25,26]$. The combination of multi-source data of technology contributes to incorporate more information to carry out a more comprehensive analysis of technology evolution. However, these studies lack the semantic analysis of the contents of scientific literature and make it difficult to dig into the contents to investigate the evolution trend of technology [15]. Because literature can enable us to obtain the solutions to specific problem and learn the creation of a new idea, a large amount of information reflecting the technology development exist in the contents of scientific literature. Implementing detailed mining of literature contents can help us obtain deeper insight into technology development [11]. To effectively process and analyze the contents of scientific literature, machine learning method based on topic models has been proposed and widely used in technology mining tasks in recent years [27-33]. The topic models in above works can be applied to mine a large amount of literature contents to obtain latent intellectual structures of technology focuses related to a specific domain, which can model the inherent heterogeneous structures within technology. However, the limitation of the above works is to choose only papers for analysis and lack multi-dimensional data association and integration to explore the evolution of technology.

Few studies attempted to perform large-scale and systematic analysis of a machine tool. To investigate the development of the machine tool domain, we proposed an integrated approach framework in this paper. The proposed framework combined machine learning, trend analysis, patent analysis and bibliometric to analyze multi-source literature related to machine tool systematically, including papers, funds, patents and news. What's more, the integrated framework proposed in this paper could analyze the evolving situation of the machine tool domain from multi-view perspectives of research, technology development and business mode. Concretely, machine learning method based on topic models was applied to obtain existing intellectual structures of research focuses within the machine tool domain. The trend analysis method models the dynamic evolution over time for the extracted research focuses to reflect future research trends. Science funds is an important dimension reflecting research activity and bibliometric is used to analyze the funds of the National Science Foundation (NSF) related to machine tool as a complement to the analysis of papers. In order to study the technology development of machine tool, the proposed approach used patent analysis methods, including patent development trajectories and institutional cooperation networks to analyze patents based on the exploration of the above research perspective. Finally, the topic model extracted the latent intellectual structures from the latest news contents related to the business of a machine tool to model the business focuses on the machine tool industry. As a result, the framework proposed by us can carry out multi-dimensional and semantic analysis of multi-source data to explore the development of machine tools from multi-layered perspectives.

The rest of this paper is organized as follows: Section 2 reviews the related researches. Section 3 presents the main framework proposed and the data applied for subsequent analysis. Section 4 shows the experiments and discussions. Section 5 discusses the sustainability implications of the machine tool domain, and, finally, Section 6 concludes this paper. 


\section{Related Work}

Although much attention has been paid to explore the development of specific technology in these years, existing methods are limited in terms of taking the whole ecosystem of the technology domain into consideration when analyzing the development status of the domain. In this section, we review recent progress on the task of technology exploration analysis and give a summary.

\subsection{Analysis of Machine Tool Development}

Recently, machine tool domain has been given new connotations and entered a new stage of development [7]. Many scholars adopted a qualitative review method of literature to explore the status and trend of machine tools [8-10]. Tang provided a state of the art review on algorithms for collision detection in five-axis NC machining and explored the challenges that needed to be addressed further [34]. Lauro et al. presented a brief review of monitoring techniques and signal processing methods applied in machining processes to identify technology focuses in that field [35]. Cao et al. carried out an in-depth review of the state-of-the-art progress of intelligent spindles and prospected future trends of technology [36]. In addition, similar works include a qualitative review of papers literature belonged to a specific technology, such as spindle thermal error compensation, reliability analysis, and reconfigurable machine tools, to identify focuses and explore trends of specific technology [37-39]. The characteristics of these studies are based on the expert's experience to conduct an in-depth qualitative review for papers related to a sub-technology of machine tools and analyze the current progress and future trends of the technology. However, given the limited research scope and energy of a single expert it is difficult to analyze a large number of related papers by reading them. As a result, the above literature review method is incapable of keeping up with the rapidly increasing number of papers comprehensively in the whole machine tool discipline, which makes it hard to analyze and track the development of the machine tool, systematically. In addition, the application of qualitative review method based on papers above is difficult to generalize to a comprehensive analysis of the future development of the entire machine tool domain.

Some other researches aimed to study the development of the entire machine tool field $[4,7,40]$. For example, Liu et al. proposed a new generation of machine tool, i.e., cyber-physical machine tool as a development direction of machine tools technology [5]. However, these works depended only on the experience of experts. The conclusions are easy to generate knowledge solidification and make predictions along the existing technology paradigm, resulting in their objectivity, consistency and validity are limited [12,13]. In particular, the impact of the new-generation information technology on machine tool field runs through the entire technology cycle and it is essential to carry out multi-dimensional analysis, including research, technology development and business to clarify the development trajectories and current concerns of the machine tool. However, the existing works lack a multi-layer analysis of machine tool activities.

\subsection{Bibliometric and Patent Analysis for Technology Evolution}

Compared with a qualitative review method, the use of quantitative analysis method can provide objective information to explore technology development based on available abundant scientific literature [19,41]. Many researchers have adopted the bibliometric, or patent analysis, method to investigate the evolution of technology $[17,18,41,42]$. Marzi et al. provide insights about future research avenues in the manufacturing field by conducting a bibliometric analysis about the innovation of product and process in the manufacturing [16]. Ernst analyzed the patents in the machine tool industry to detect and trace the development of CNC technology [21]. The quantitative analysis methods help to relieve the limitations of the objectivity and validity that exist in the qualitative review method to a certain extent [22,23]. However, current works only analyze a single data dimension (papers or patents) and ignore conducting a collaborative analysis of multi-source data (such as papers, patents, funds, and news) to explore the development and change of technology from a more comprehensive 
perspective. Multi-dimensional literature maps all aspects of technical activities and includes richer information on domain development. Recently, more and more works have focused on the integration of multi-source literature to conduct technology evolution analysis [26]. Wang et al. carried out a review and forecast of emerging technology in nanogenerator using integrating methods to analyze papers and patents literature [25]. Xu et al. conducted a method to explore the innovation capacities of a multi-layered innovation ecosystem, merging publication data, patent data and business data [43]. Multi-source data integration enables analyzing the development of the technology domain more objectively. However, no work attempts to analyze the multi-source literature regarding machine tools in order to explore and clarify its development. Moreover, the existing quantitative studies of multi-source data used for technology evolution consider limited information and lack in-depth semantic analysis of the content of scientific literature [15].

\subsection{Machine Learning Method in Emerging Technologies Analysis}

The contents of the scientific literature contain an abundant amount of information and knowledge reflecting the technology concerns and development trends. Further exploration and understanding of the literature contents will help us gain insights into the evolution of technology [31]. In order to deeply analyze the contents of scientific literature, machine learning method based on topic models has been widely used in analysis tasks of technology development in recent years [27-30,33]. Yang et al. explored the research trending topics of smart factories using topic modeling method to determine the future research directions [11]. Abuhay et al. modeled the underlying topical structures of the International Conference on Computational Science and provided insights regarding the past and future technology trends in computational science [32]. In these works, topic models mined a large amount of literature contents to obtain latent intellectual structures of focuses related to a specific technology domain, which could be used subsequent technology forecasting task. To the best of our knowledge, no research has been done applying topic models to perform a large-scale and systematic research of scientific literature related to machine tools. In addition, existing works have the following limitation. Specifically, the current works consider a single data dimension for analysis and lack the association and integration of multi-dimensional data. This makes it difficult to explore the future evolution of the technology domain collaboratively from the multi-perspective, such as research, technology development and business.

Compared with a qualitative literature review method, quantitative methods can improve the objectivity and validity of analysis results. Moreover, the integration of multi-source literature can analyze the development of the technical domain more comprehensively. Furthermore, the topic model can conduct semantic analysis for the contents of the literature to model complex inherent heterogeneous of the technology. Based on the above analysis and in light of the complex characteristics of the machine tool domain, in this paper we proposed an integration framework combining machine learning and other data mining approaches to analyze multi-source literature related to machine tool and explore the development of this domain from multi-perspective, including research, technology development and business.

\section{Method and Data}

In this section, we will discuss the proposed framework and literature data for analysis in this paper. Specifically, in Section 3.1 we will first discuss the research framework to explore the development of the machine tool domain from multiple-dimension perspectives. Then in Section 3.2, we will discuss the acquisition of multi-source literature data on machine tools. Finally, in Section 3.3 we will detail discuss the topic model, which is a core component of the proposed framework.

\subsection{Method Framework}

As it is critical to identify and grasp the opportunity to develop machine tool, clarifying the development of the machine tool domain is an important question to be solved. In light of the 
emerging information technologies penetrate all aspects of the machine tool domain, the above problem can be broken down into the following three sub-problems. First, what new changes occurs in the research on machine tools under the influence of the new-generation information technology? Second, what impacts emerging information technologies have on technology development of machine tool? Third, what emerging business modes emerge in the machine tool industry? In order to solve the above problems, this paper developed an approach framework, as shown in Figure 1. The proposed framework is based on the integration of four methods, including topic model, trend analysis, patent analysis and bibliometric.

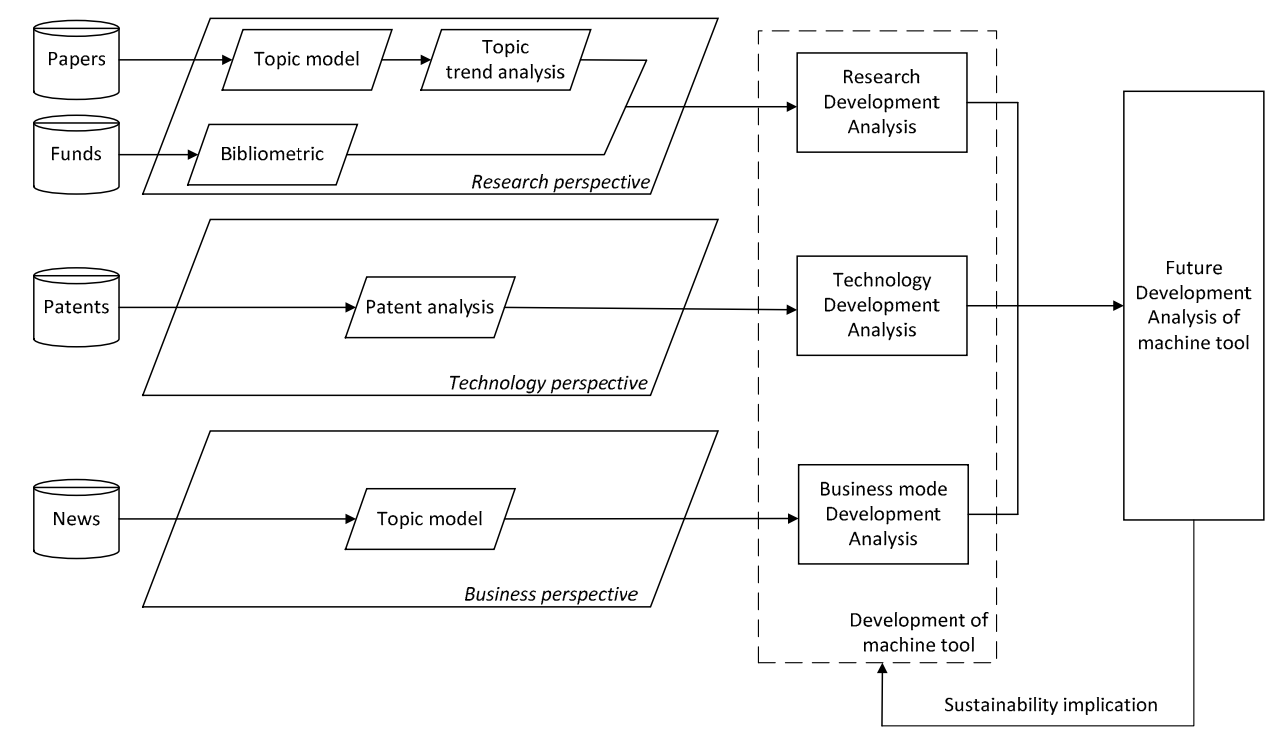

Figure 1. The analytical framework of machine tool development.

This framework explored the development of research, technology and business in the machine tool discipline by analyzing multi-source data related to machine tools. Specifically, we mainly select literature of papers to analyze the research evolution of the machine tool, as papers are a source of knowledge that maps specific discipline research activities and contains sufficient information for reflecting current development and future trend of that discipline [15]. The papers reflect the output of the research activity, while the funds reflect the input of the research. Compared with papers, the funds contain some additional information on the people, inputs and processes of science activity [44]. We choose the literature of funds related to machine tool to conduct an auxiliary analysis for the research development. The literature of patents is a mapping of technology development in a specific domain.

For this reason, the patents have been considered by us as a source of fruitful knowledge to identify technology development in practical applications [45]. We choose patents to investigate the new changes in technology development of machine tools. Given the fact that the Google searches publications of news written to reflect the business and market, we apply the Google news related to machine tool industry to analyze the new changes of business modes in this industry [46]. Data collection methods and pre-processing steps will be discussed in Section 3.2.

The integrated framework proposed above is used to analyze the multi-source literature data on machine tools. In order to analyze the research development of machine tool, a topic model is used for mining latent intellectual structures of research concerns from the literature. Then based on topic strength development through time of modeled research focuses, we conduct trend analysis by way of the Mann-Kendall test method and predict the development trend of research focuses [47]. As a useful supplement to the literature of papers, a simple bibliometric analysis of funds is carried out as an auxiliary perspective to explore the research development of machine tools. Furthermore, patent analysis methods (including Patent growth trajectory and Institutional cooperation network) 
are applied to analyze the technology development of the machine tool. Patent growth trajectory can reflect the development status of technology very well [48]. Finally, in order to clarify the problem of the change of the machine tool business mode, a topic model is used to mine the latent intellectual topics of business focuses on the collected news. The advantage of the approach framework proposed is that it can integrate semantics, time dynamics and the fusion of multi-dimensional data to carry out multi-perspective evolution analysis of the machine tool domain in a complex environment. As the machine tool industry is one of the typical industries that generate resource consumption and emit environmental pollutants, it is essential to explore the sustainable development of machine tools in the future. To this end, based on the explorations of the emerging changes and future development trends of machine tools, we discuss the sustainable development of machine tools. The main machine learning method involved in our framework will be discussed in Section 3.3 below.

\subsection{Data Collection}

In this study, we selected papers, funds, patents, and news related to the machine tool domain to analyze its development. This section will discuss in detail the acquisition method and pre-processing steps of data used for analysis.

Papers data used in experiments were searched from Science Citation Index Expanded (SCI-EXPANDED) and Social Sciences Citation Index (SSCI) databases, on the Web of Science, which are the most authoritative scientific and technical literature indexing tool [49]. The search time of SCI-EXPANDED database was set from 1997-2018 as SCI-EXPANDED did not contain data before the year of 1997. For the same reason, the time range of the SSCI database was set from 2000-2018. In addition, in order to ensure the quality of the retrieved data and facilitate subsequent analysis, when retrieval we restricted results by the English language and set document type as Article. Based on the above settings, we searched papers literature that contained terms, such as "Machin* tool*", "machin* center", "milling center" and "NC machin" et al. as the raw data. The raw papers collected included the title, abstract, author, publication year, source and other field information. Because the abstract is a compact representation of paper, we chose the exported abstract field to represent a paper for subsequent analysis. The raw text content of the abstract field contains a lot of noise information that hinders subsequent data mining analysis. We performed the pre-processing steps listed in Table 1 below to remove the noise information. Among which, Natural Language Toolkit (NLTK) stop words list is a commonly used stop word list in natural language processing, including a, the, of, for, etc. that do not contain valuable information to comprehend the implication of technology. In addition, The CNC machine tool domain stop words list refers to the list of stop words specific to the machine tool, including words, such as abstract, paper, experiment, method, etc., which also do not contain valuable information for exploring the development of the domain. After pre-processing steps, we collected 7832 papers to constitute the final dataset of papers for analysis experiments.

Table 1. Pre-processing steps.

\begin{tabular}{cl}
\hline Step & \multicolumn{1}{c}{ Description } \\
\hline 1 & Remove repeat document \\
2 & Remove stop words from NLTK stop words list \\
3 & Remove stop words from CNC machine tool field stop words list \\
4 & Remove low and high frequency words \\
5 & Remove abstract whose length less than 20 \\
\hline
\end{tabular}

For funds related to research, we extracted from the NSF award database. NSF is a federal funding agency and searching the NSF award database allows for the retrieval of the whole awards issued by the NSF [44]. In this paper, we used the keywords "Machin* tool" ", "machin* center*", "milling center*" and "NC machin*" et al. to retrieve funds related to machine tool and time range was set from 1984 to 2019. Then 675 awards were retrieved from the NSF award database. As for patents analyzed in this 
paper, we built a unique patent database on machine tool from Derwent World Patents Index database with a time range from 1997 to 2018. We searched the patents belonging to the two IPC classification numbers, i.e., B23 and G05B001918. The specific retrieve keywords are given in Section 4.2. The reason for selecting these two IPC classification numbers is that the B23 classification number indexes patents within the machine tool domain, and G05B001918 indexes the patents related to the numerical control system. Finally, we obtained 10090 patents for subsequent experiment analysis and we also chose the patent abstract information as a proxy for the patent. As for the news related to machine tool business, we selected the keywords "business model", "market trend", "future trend" OR "new mode" et al. within the range of machine tools represented by the keywords of "Machin* tool" ", "machin* center*", "milling center" and "NC machin*" to retrieve relevant news from Google search with time range from 2015 to 2019. Then we used the crawler tool to crawl the search results from Google Chrome. The acquired dataset of news was used for subsequent data analysis after the pre-processing steps shown in Table 1. After removing the noise data, the final result containing 1120 news was obtained. The various multi-source data information related to the machine tool field is summarized in Table 2.

Table 2. Information summary of multi-source data related to machine tools.

\begin{tabular}{ccc}
\hline Dataset & Source & Number \\
\hline Papers & Web of Science & 7832 \\
Funds & National Science Foundation (NSF) award database & 675 \\
Patents & Derwent World Patents Index database & 10,090 \\
News & Google News & 1120 \\
\hline
\end{tabular}

\subsection{Topic Model}

Given a document corpus, the purpose of the topic model is to allow users to explore the hidden intellectual structures behind the corpus in the form of topics. Latent Dirichlet Allocation (LDA) has been widely used for inferring latent topics from document collections based on the basic assumptions that each topic is represented as a multinomial distribution over vocabulary, and each document is represented as a multinomial distribution over these topics [27]. In this paper we use LDA to extract research and industry focus from document corpus related to machine tools. In this section we discuss the principles of LDA in detail. The notations and their corresponding meanings used in this paper are summarized in Table 3.

Table 3. Notations used in topic modeling.

\begin{tabular}{cc}
\hline Notations & Meaning \\
\hline $\mathrm{M}$ & Number of documents in the corpus \\
$\vec{d}$ & Documents in the corpus \\
$\mathrm{V}$ & Number of words in the vocabulary \\
$\mathrm{K}$ & Number of predefined latent topics \\
$N_{m}$ & Number of tokens in document $\mathrm{m}$ \\
$\mathrm{m}, \mathrm{k}, \mathrm{n}, \mathrm{t}$ & Index for document, topic, token in a document, years \\
$\vec{\theta}_{m}$ & Multinomial distribution over topics for document $\mathrm{m}$ \\
$\theta_{m}^{k}$ & Proportion of topic $\mathrm{k}$ in document $\mathrm{m}$ \\
$\vec{z}_{m}$ & Topic labels of document $\mathrm{m}$ \\
$\vec{\varphi}_{k}$ & Multinomial distribution over words for topic $\mathrm{k}$ \\
$n_{m}^{(k)}$ & Number of tokens assigned to topic $\mathrm{k}$ in document $\mathrm{m}$ \\
$\neg i$ & Word $w_{i}$ is excluded from the counting \\
$n_{k}^{\left(w_{i}\right)}$ & Number of times of word $w_{i}$ assigned to topic $\mathrm{k}$ \\
$\mathrm{I}$ & Number of iterations \\
$n_{m}$ & Number of topics in document $\mathrm{m}$ \\
$n_{k}$ & Number of words in topic $\mathrm{k}$ \\
$\alpha, \beta$ & Parameter of Dirichlet distribution for $\vec{\theta}_{m}$ and $\vec{\varphi}_{k}$ \\
$t_{m}$ & Publication year of document $\mathrm{m}$ \\
$\theta_{k}^{t}$ & Proportion of topic $\mathrm{k}$ at year $\mathrm{t}$ \\
\hline
\end{tabular}


The graph model of LDA is shown in Figure 2. Given a document collection containing M documents, the dictionary generated by this collection consists of $\mathrm{V}$ different words. We assume the number of latent topics contained in this collection is $\mathrm{K}$.

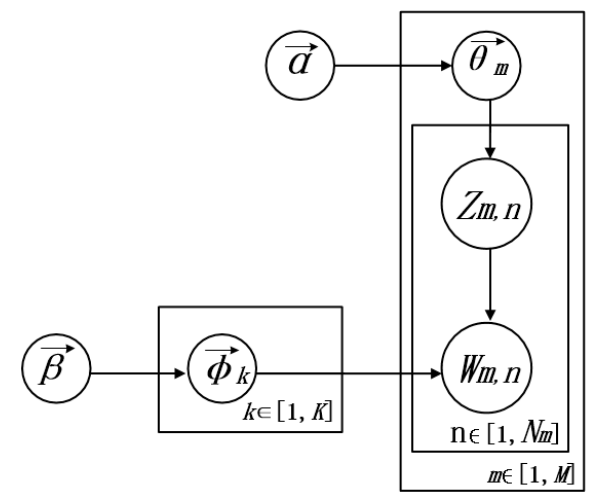

Figure 2. Graphical model of Latent Dirichlet Allocation (LDA).

LDA is a probabilistic generative model. When generating the $m$ th $(m \in[1, M])$ document in corpus, LDA samples a topic multinomial distribution $\vec{\theta}_{m}$ for the document $m$ from a Dirichlet prior distribution with hyper-parameter $\vec{\alpha}: \mathrm{p}\left(\vec{\theta}_{m} \mid \vec{\alpha}\right)=\operatorname{Dir}\left(\vec{\theta}_{m} \mid \vec{\alpha}\right)$ where $\vec{\alpha}$ and $\vec{\theta}_{m}$ are both $K$ dimensional vectors and the elements of $\vec{\theta}_{m}$ are satisfied with: $\sum_{k} \vec{\theta}_{m, k}=1, k=1, \ldots, K$. Then LDA assigns a latent topic $z_{m, n}$ for each word $w_{m, n}$ in document $m(m \in[1, M])$ based on the topic multinomial distribution $\vec{\theta}_{m}$ of the $m t h$ document. $N$ characterizes the position of the word in the document and satisfies collection $n \in\left[1, N_{m}\right]$, where $N_{m}$ states the number of words in document $m$. Assuming all words is independent of each other in a document, for document $m$ the joint probability of topic assignments for all words in LDA is shown in Formula (1).

$$
\mathrm{p}\left(\vec{z}_{m} \mid \vec{\theta}_{m}\right)=\prod_{n=1}^{N_{m}} \mathrm{p}\left(z_{m, n} \mid \vec{\theta}_{m}\right)
$$

where $\vec{z}_{m}$ characterizes topic assignments for all words in $m$ th document.

As discussed above, the $k t h$ topic is assumed to be a multinomial distribution over $V$ words in the dictionary. According to LDA, each multinomial distribution of topic $\vec{\varphi}_{k}$ follows a Dirichlet prior distribution with hyperparameters $\vec{\beta}: \mathrm{p}(\varnothing \mid \vec{\beta})=\operatorname{Dir}\left(\vec{\varphi}_{k} \mid \vec{\beta}\right)$, where both $\vec{\varphi}_{k}$ and $\vec{\beta}$ are $V$ dimensional vectors. $\varnothing$ denotes a matrix with $K \times V$ dimension containing all topics' multinomial distributions. $\vec{\varphi}_{k, w}$ denotes the probability of generating word $w$ given topic $k$ and it satisfies $\sum_{w} \vec{\varphi}_{k, w}=1$, where $w$ $=1, \ldots, V$. Then each word in document $m$ can be generated by sampling from the corresponding multinomial distribution of latent assignment topic: $\mathrm{p}\left(w_{m, n} \mid z=z_{m, n}\right)=\vec{\varphi}_{z_{m, n}}$.

Given a document collection, $w_{m, n}$ is observable variable, $\alpha$ and $\beta$ are prior hyper-parameters. $z_{m, n}, \vec{\theta}_{m}$ and $\vec{\varphi}_{z_{m, n}}$ are hidden variables which can be estimated by the observed words in the corpus. The joint distribution of all variables is as follows:

$$
\mathrm{p}\left(\vec{w}_{m}, \vec{z}_{m}, \vec{\theta}_{m}, \varnothing \mid \vec{\alpha}, \vec{\beta}\right)=\prod_{n=1}^{N_{m}} p\left(w_{m, n} \mid \vec{\varphi}_{z_{m, n}}\right) \cdot p\left(z_{m, n} \mid \vec{\theta}_{m}\right) \cdot p\left(\vec{\theta}_{m} \mid \vec{\alpha}\right) \cdot p(\varnothing \mid \vec{\beta}) .
$$

The hidden variables in the generative process can be approximated by applying the Gibbs Sampling method. The parameters inference method of Gibbs Sampling has been widely used in 
various parameters estimating of topic models. We can derive the conditional distribution for sampling a topic $\mathrm{z}$ for each word of the corpus in every iteration as follows:

$$
\mathrm{p}\left(z_{i}=k \mid \vec{z} \neg, \vec{w}\right) \propto \frac{n_{m, \neg i}^{(k)}+\alpha}{\sum_{k=1}^{K}\left(n_{m, \neg i}^{(k)}+\alpha\right)} \cdot \frac{n_{k, \neg i}^{\left(w_{i}\right)}+\beta}{\sum_{i=1}^{V}\left(n_{k, \neg i}^{\left(w_{i}\right)}+\beta\right)} .
$$

Figure 3 presents the abstract of a randomly selected machine tool paper and the results of the topic modeling. The selected paper discusses cloud service mode in machine tool manufacturing. Compared with other topics, Topic 174 has a much higher proportion in modeling results. It can be seen from the word distribution under Topic 174 that the topic is mainly about cloud services, which demonstrates the effectiveness of topic modeling.

the globalised machine-tool manufacturing enterprises are eager to develop intelligent machine tools and novel business models to increase their competitiveness in recent years cloud manufacturing encapsulating distributed manufacturing resources into cloud services for supporting all tasks in a product life cycle has emerged as a promising concept and approach for the machining industry to achieve such a goal and gain profits however there has been no systematic approach to the development of cloud manufacturing systems cmss for the machining industry so far in this paper we propose a novel cloud manufacturing framework cmf with auto-scaling capability called cmfas aimed at providing a systematic and rapid development approach for building cmss the proposed cmfas contains a cloud-based architecture which can transform single-user manufacturing functions mfs into cloud services......

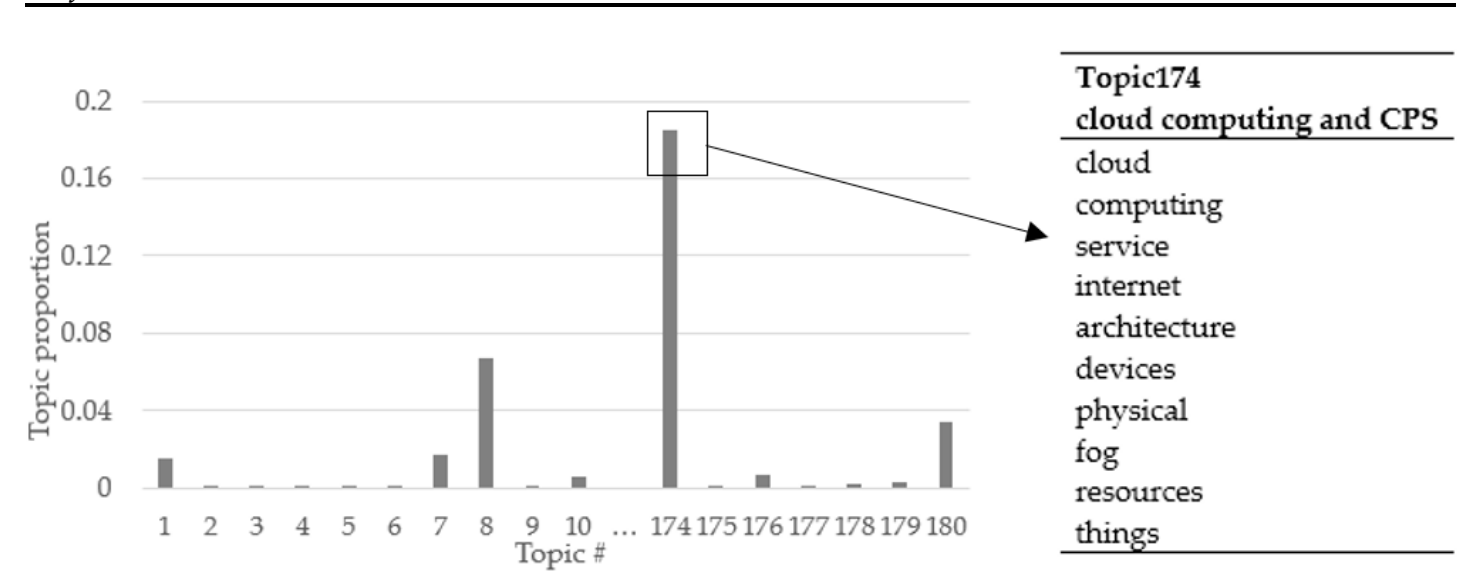

Figure 3. Topic modeling result of paper abstract.

\section{Results and Discussions}

This section presents the results of the experimental analysis and discussions. Concretely, Section 4.1 presents data mining results for papers and funds to analyze current focuses and development status of the machine tool domain under a research perspective. Then, Section 4.2, discusses the analysis of patents to explore the technology development of machine tools. In Section 4.3 we explore the changes in the business mode of the machine tool industry through the analysis of news. Finally, in Section 4.4, we conduct a deep joint analysis of machine tool development merging multi-perspectives and make predictions about the future development of machine tools. 


\subsection{Analysis to Research Development of Machine Tool}

\subsubsection{Topic Modeling of Machine Tool Papers}

In this section, we conducted topic modeling for papers of the machine tool domain to mine intellectual structures of research concerns. As discussed earlier, the LDA model has been widely used in topic extraction tasks. Previous studies have shown that consider only statistical indicator to determine the hyper-parameters of the LDA may produce incoherent topics which constitute the primary obstacle to acceptance of topic models in practice [50,51]. The main reason lies in the objective function of the LDA model may not correlate well with human judgments [52]. In order to model the research concerns in machine tools more accurately, we used manual inspection method to adjust LDA to optimize the modeling effect and determine the hyper-parameters. Upon manual inspection, we found that 180 topics resulted in a granularity that better captures the scientific intellectuals within the machine tool domain, i.e., $K$ was set 180 . As for other hyper-parameters $\alpha, \beta$ and I, we recommended setting $\alpha=0.1, \beta=0.01$ and $\mathrm{I}=1000$. Under this set of hyper-parameters, the LDA model works best. After completing the topic modeling of the machine tool papers, we adopted a manual interpretation method to check the mined research topics and removed noisy topics. The noise topic refers to a topic that does not reflect a clear technology meaning as a whole. For example, a modeled topic consists of words, such as "size", "average", "sample", "factor", "small" and "large" etc. To facilitate subsequent analysis, we removed these noise topics and finally obtained 158 topics. Due to the space limit the overall topic modeling results of machine tool papers are shown in Table A1, in Appendix A. Some of the typical results we selected are shown in Table 4 below. Every piece of intellectual structures modeled is characterized by 15 high frequency terms. Furthermore, based on prior domain knowledge, we labeled each topic and mapped it to the actual research concern of machine tool, as seen in the "meaning column" in Table A1. In addition, we conduct a set of experiments to verify the stability of our analysis. In each experiment, $25 \%$ of the papers are excluded randomly from the original paper dataset. Then, we run LDA on the obtained four new paper datasets, respectively. The parameters of LDA follows the settings above. We count the total number of topics remodeled in each experiment and calculate the ratio. The statistical results are shown in Table A2, in Appendix B. Experimental results demonstrate the stability of the analysis.

Table 4. Examples of the topic modeling results of machine tool papers.

\begin{tabular}{ccl}
\hline Meaning & Topic & \multicolumn{1}{c}{ High-Frequent Terms } \\
\hline Online monitoring & Topic 13 & $\begin{array}{l}\text { Sensors, monitoring, sensing, system, online, fusion, measurements, } \\
\text { wireless, information, signals, in-process, installed, sensory, } \\
\text { monitor, integration }\end{array}$ \\
\hline Tool path planning & Topic 64 & $\begin{array}{l}\text { Tool, cutter, surface, path, machining, orientation, five-axis, method, } \\
\text { contact, paths, orientations, point, location, positioning, generate }\end{array}$ \\
\hline
\end{tabular}

We further give a brief analysis and explanation for the topic modeling results of the machine tool papers. For example, Topic 92 is composed of terms like "vibration", "frequency", "amplitude", "mode", "resonance" and "suppression" etc., which refers to the research point of "vibration suppression". Topic 133 consists of "component", "structural", "design", "mechanical", "performance" and "topology" etc., which reflects "structure design" of machine tools. Based on prior domain knowledge, we can infer that both of the above topics are sub-areas of machine tool design research. Furthermore, Topic 25 (characterized by "measuring", "inspection", "coordinate", "system", "error", and "profile" etc.) refers to "profile control", which belongs to research category of the numerical control system. In addition, many topics in modeling results reflect technologies related to the processing system in the machine tool. For example, Topic 64 characterizes "tool path planning" concern. Based on our domain knowledge, the latent intellectual structures obtained by topic modeling are highly correlated with the actual research activities of machine tools. In addition, many research concerns obtained 
by LDA model exceed the standard research scope of machine tools domain. For example, Topic 139 contains words like "learning", "deep", "algorithms", "representations", "convolutional" and "temporal", which refers to "deep learning" technology in artificial intelligence (AI). To the best of our knowledge, deep learning is the research frontier and hot spot of current AI. The topic mining results reflect that deep learning has been applied to research exploration in the field of machine tools and has become a research focus in this field. Similar research focuses are abundant in the modeling results like Topic 153, etc., indicating that emerging changes have occurred in the research on machine tools.

\subsubsection{Analysis of Research Development in Machine Tool Domain}

In order to explore the impact of the new-generation information technology on machine tool research activities further, we divide the research concerns generated in Section 4.1.1 to which it belongs according to the category of the machine tool domain, as shown in Table 5. Based on prior domain knowledge, we can classify the category of machine tool technology into "machine tool body and design", "machine tool components", "numerical control system", "process system" and "machine tool industry", et al., which conforms to the conventions of the traditional machine tool community. In addition, the category of "machine tool industry" consists of some research concerns about the management of the machine tool industry. The reason lies in our dataset of paper contains some SSCI papers which cover the management aspects of machine tools. Among all categories, the "Process System" category and "Numerical Control System" category contains the largest number of research concerns, accounting for $34.8 \%$ and $19.0 \%$ of the total research concerns respectively. According to domain knowledge, these two categories are the focuses of the research in the machine tool domain.

Table 5. Categorization of machine tool research concerns.

\begin{tabular}{cl}
\hline Category & \multicolumn{1}{c}{ Topic Index } \\
\hline \multirow{2}{*}{ Machine Tool Body and Design } & $\begin{array}{l}3,7,9,12,26,29,37,41,44,51,56,71,76,77,80,92,102,110, \\
133,137,143\end{array}$ \\
\hline Machine Tool Components & $2,6,32,42,46,61,73,84,87,95,99,105,106,111,119,134,154$ \\
\hline \multirow{2}{*}{ Numerical Control System } & $10,13,16,20,22,25,27,36,63,67,68,74,78,83,86,88,90,93$, \\
& $100,107,112,114,121,125,128,129,132,136,144,151$ \\
\hline & $4,5,11,15,18,19,21,23,24,28,31,33,38,39,43,45,47,49,50$, \\
& $52,53,54,55,59,60,64,66,69,70,72,75,81,85,89,94,96,98$, \\
& $108,109,113,116,117,130,138,140,141,145,146,147,148,149$, \\
& $150,152,156,157$ \\
\hline Machine Tool Industry & $8,14,30,48,91,124,126,155$ \\
\hline Smart Machine Tool & $40,57,101,123,153$ \\
\hline \multirow{2}{*}{ Intelligent Machine Tool } & $1,17,34,35,58,62,65,79,82,97,103,104,115,118,120,122$, \\
\hline
\end{tabular}

However, by analyzing the results of the topic modeling, we can find a considerable amount of research concerns exceed the traditional machine tool category. For this reason, we cannot simply divide them into the original machine tool categories. After conducting an in-depth analysis of these results, we find these concerns reflect new developments in machine tool research under the influence of emerging information technologies. Based on the characteristics of these research focuses, we divided them into two new categories labeled "smart machine tool" and "intelligent machine tool" respectively in Table 5. Concretely, the "smart machine tool" category contains research focuses, such as "internet of things (IoT)", "protocol and security of IoT", "big data", "distributed platform" and "cloud computing and Cyber-physical system". The above research concerns are closely related to emerging information technologies, reflecting that the interconnection of machine tool equipment and the collection of machine tool big data is getting more and more attention from scholars within 
the domain. For "intelligent machine tool", this category contains research concerns like "deep learning", "machine learning", "neural network", "expert system" and "heuristic algorithm" et al. These concerns are all about intelligent analysis methods. Among them, deep learning is leading the rapid development of artificial intelligence domain with its powerful feature representation learning ability. In addition, this category also includes research of intelligent application technology on machine tool supported by intelligent analysis methods, such as "prognostics and health management of machine tool" and "machine tool condition monitoring". The categorization of "intelligent machine tool" shows that intelligent methods, such as deep learning and its application in the machine tool domain have become the focuses on research and much attention has been paid on the direction of machine tool intelligence. Through the above investigation, we can conclude that the integration of the new-generation information technology and machine tools has brought significant changes to the research system of the machine tool domain, which has generated new exploration directions outside the traditional research scope of machine tools. Researchers are beginning to focus on the integration of machine tools with artificial intelligence, industrial internet of things, big data analytics, cloud computing and cyber-physics systems to enable machine tool to operate in a more flexible, efficient, energy-efficient and sustainable manner.

Based on the above analysis, we selected the representative research concerns in the two categories of "smart machine tool" and "intelligent machine tool" to draw the evolution river map during the research process of machine tools. Evolution river map aims at displaying the impact of the new-generation information technology on the research activities of machine tools more intuitively, which is shown in Figure 4 below. The width of the evolution curve for each particular research concern selected in each year is proportional to the topic strength of the research concern that year. The calculation formula of topic strength for a specific technology is as follows.

$$
\theta_{k}^{t}=\frac{\sum_{m=1}^{M}\left(\theta_{m}^{k} \times \mathrm{I}\left(t_{m}=t\right)\right)}{\sum_{m=1}^{M} \mathrm{I}\left(t_{m}=t\right)},
$$

where $M$ is the number of papers in the corpus and $t_{m}$ is the publication year of paper $m . I(\cdot)$ denotes indicator function, which will take a value of 1 when the expression in parentheses is true, otherwise 0 when the expression is false.

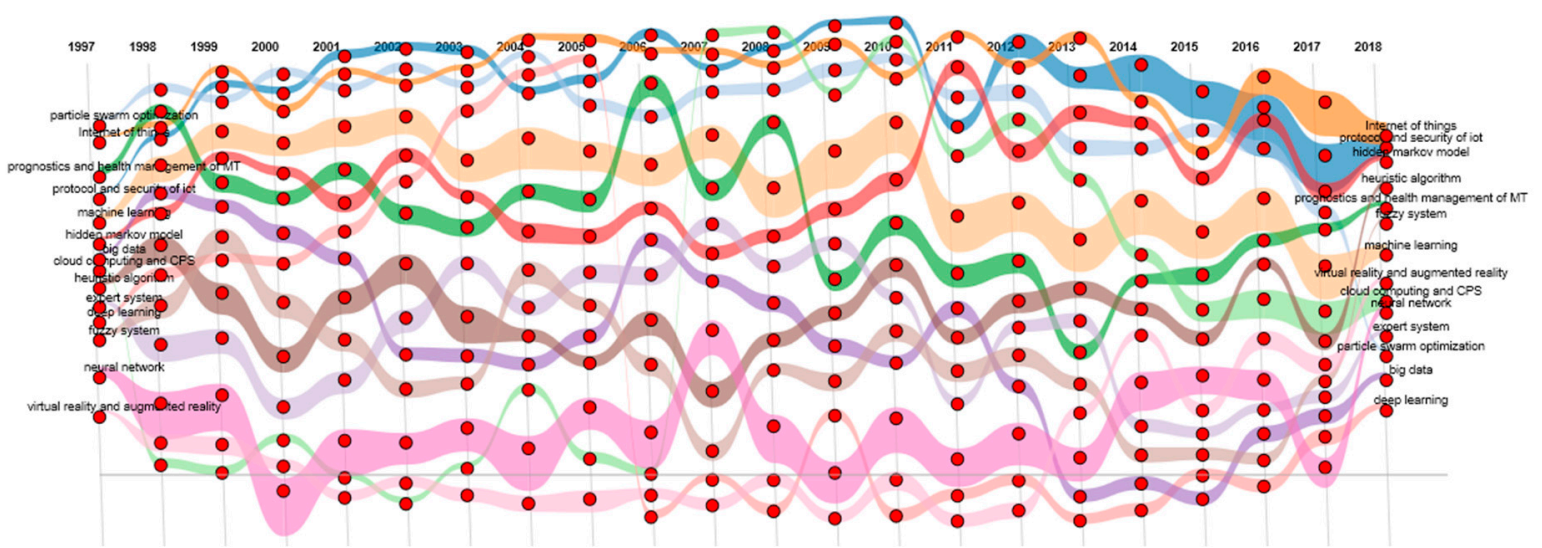

Figure 4. The evolution river map of the selected research concerns.

From the river map of technology evolution, we can see that the research concerns like "internet of things", "protocol and security of IoT", "cloud computing and cyber-physical system", "machine learning" and "deep learning", etc., have gradually become more and more important in the research community of machine tools. This further clarifies the characteristic of gradual integration between machine tool research and emerging information technologies. 


\subsubsection{Topic Trend Analysis}

The above discussion analyzes the emerging research concerns that occur in the research community of machine tools, and the evolution of the selected representative emerging concerns in the research process of machine tools. In this section, we further explore the future development trend of these emerging research concerns generated in the machine tool domain. In the experiment, we focused on the research topics contained in the two categories of "smart machine tool" and "intelligent machine tool" in Table 5. These two categories best reflect the new changes in research ecology of machine tools. According to Formula (4), we calculated the topic strength of 27 elements under two categorization year by year and further obtained the evolutionary sequence of 27 elements over time respectively. Then we used the Mann-Kendall trend analysis method to detect the rising or falling trend of the selected research focuses [47]. Through trend analysis, "protocol and security of IoT", "internet of things", "big data" and "cloud computing and CPS (cyber-physical system)" in the "smart machine tool" category showed a significant rising trend, as shown in the following Figure 5a. This suggests the fact that these technologies will become increasingly important in future research of machine tools. Furthermore, for the "intelligent machine tool" category, "deep learning", "machine learning", "hidden markov model" and other seven topics presented a rising trend as shown in Figure 5b. In addition, the six research topics including "fuzzy system", "neural network", "expert system" etc. showed a significant falling trend as shown in Figure $5 \mathrm{c}$ below.

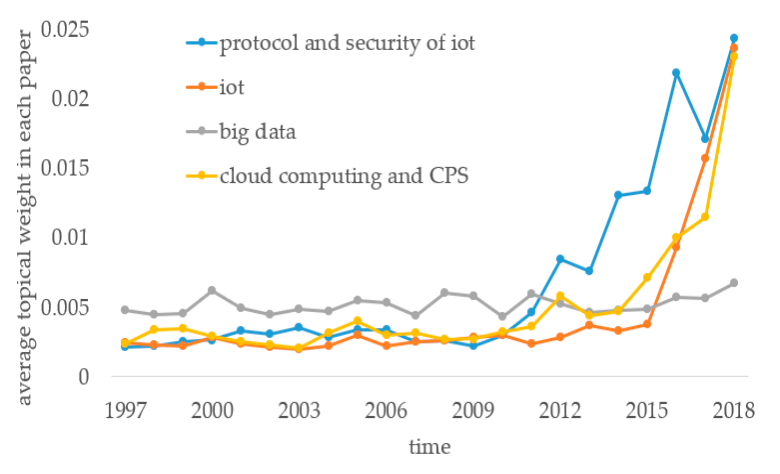

(a)

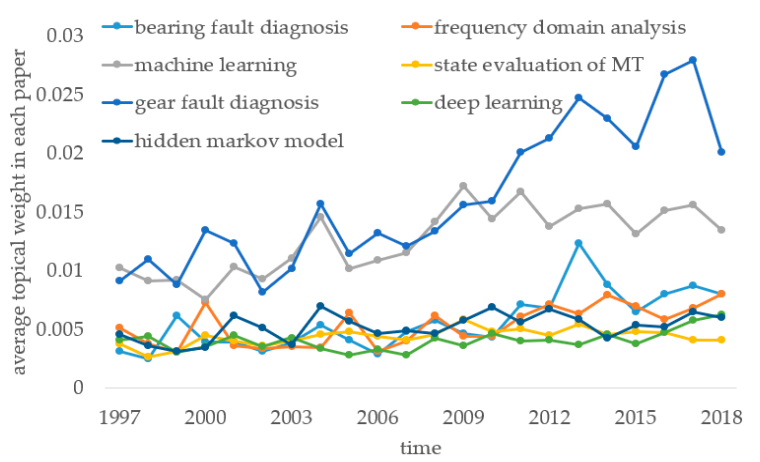

(b)

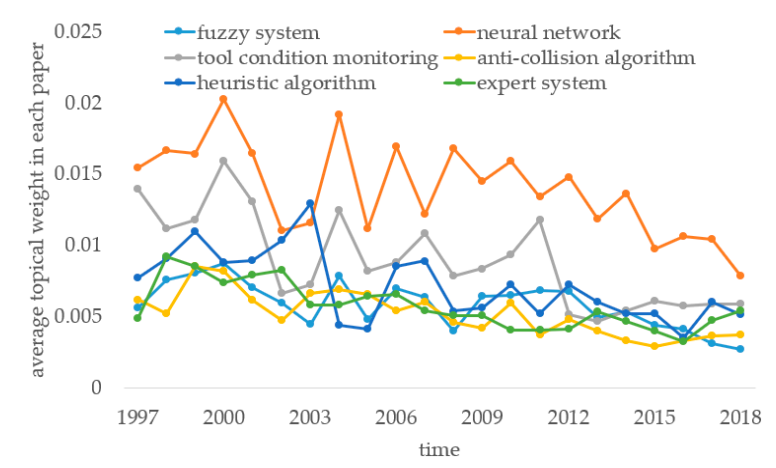

(c)

Figure 5. Research topic trends of machine tools. (a) Rising trend topics in "smart machine tool". (b) Rising trend topics in "intelligent machine tool". (c) Falling trend topics in "intelligent machine tool".

We provide brief explanations of these emerging or fading research topics. The rise or decline of a specific research topic implies deep principles of discipline development. As for emerging topics, the explanations can be made combining domain knowledge. Currently, new-generation information technology is changing the information environment of the manufacturing, which will greatly improve the performance and efficiency of physical objects. Inspired by this, researchers in the machine tool domain will also focus on the integration of external emerging technologies and machine tool 
technology. The topic of big data mainly discusses data collection, transmission, storage and fusion of multi-source heterogeneous data. As well as we know, multi-source heterogeneity is also a typical feature of machine tool data, which can explain that big data will become more and more important in the research of machine tools. In addition, big data lays the foundation for artificial intelligence to realize self-learning. The topic of cloud computing focuses on how to analyze big data efficiently to meet the speed requirements of data analysis in the industry. The practical machining process of the machine tool continues to accumulate a large amount of internal and external data, which requires real-time analysis of the data and rapid feedback of the analysis results. This real-time data analysis demand will make the topic of cloud computing attract more and more attention in future machine tool research. As for the internet of things, the topic studies how to achieve equipment interconnection. Based on domain knowledge, the interconnection of equipment will improve the ability to manage machine tool resources and the sharing of domain knowledge.

Moreover, the interconnection of machine tools will make it possible to solve the problem of accumulation and inheritance of knowledge further. The self-learning, accumulation and inheritance of knowledge is a core issue in the machine tool domain, which will further promote the attempts of researchers to solve above issue through the study of emerging information technologies. Given the special characteristic of industrial production, safety is of paramount importance. The topic "protocol and security of the internet of things (IoT)" focuses on exploring how to ensure the security of the internet of Things. The above discussions can explain the rising trend of IoT and security related concerns in the research of machine tools. As for the topic of machine learning, it aims to extract value from accumulated big data. Especially deep learning, in view of its powerful feature representation learning ability, has achieved state-of-the-art performance on many predictive tasks related to machine tools. Based above reasons, machine learning, in particular deep learning, will receive more and more focus. The exploration of these advanced algorithm models makes it possible to develop from the descriptive analysis to the diagnostic, predictive and strategic analysis, which further promotes the research of intelligent applications like fault prediction and prognostic and health management in machine tools, and help improve people's analytical decision-making ability for complex tasks under uncertain environment. The intelligent functions of machine tools will greatly reduce machine tool machining costs and increase machining efficiency. At the current time when constraints of environmental resources are becoming increasingly tight, the research of these technologies will contribute to the sustainable development of the machine tool domain. Under the synergy of big data, internet of things, cloud computing and artificial intelligence, the enhancement of the perception, analysis and control ability of the machine tool processing makes it possible to map the actual machining state of the machine tool to the virtual space. As can be seen from Figure $5 \mathrm{a}$, there is more attention focused on cyber-physical system (CPS) modeling of machine tools. The reason lies in that the fusion of the cyber and physical space will further greatly improve the traditional simulations and actual machining methods in the domain of machine tools.

For the research concerns that decline in Figure $5 c$, fuzzy system, expert system and heuristic algorithm belongs to the research category of traditional analysis methods. These methods solve some of the problems in the machine tool domain, but inevitably have many limitations, which makes them gain decreased attention. For instance, it is difficult for the expert system to acquire and represent domain knowledge of an expert, which resulted in its generalization ability in practical tasks is not strong. It is surprising that the trend of neural networks as a classical machine learning method is also declining in machine tool research. The reason lies in that the neural network refers to the shallow network and requires manual feature engineering as input. However, deep learning enables end-to-end modeling to learn features automatically. In addition, the deep learning model owes a larger capacity than the neural network, which means that the model can complete complex learning tasks. In view of the advantages of deep learning and the application of big data, deep learning has replaced the research of shallow neural networks to some extent in the machine tool domain. 


\subsubsection{Research Analysis of Machine Tools Based on Fund Data}

As research input, funds are an important dimension reflecting research activities. We retrieved the funds related to machine tool from the NSF award database to analyze the research in the machine tool domain further. The retrieval method is described in Section 3.2 and we obtained 675 funds related to the machine tool domain through retrieval. The number, over time, of machine tool funds granted by NSF is shown below.

It can be observed from Figure 6 that the number of granted funds by NSF related to machine tool has declined in recent years. The possible reason lies in that the US manufacturing industry has gradually focused on cutting-edge research, and funding awards for conventional manufacturing technologies have been reduced. Moreover, the United States is the first country in the world to research machine tool technology, and many of its machine tool technologies have gradually matured. Since the year of 2015, the number of machine tool funds is 54, accounting for $7.96 \%$ of the total number of machine tool funds granted by NSF. We further analyzed the 54 grants since 2015 and found that two research focuses on NSF funding in recent years. One of the research concerns is the "Cyber-physical system" which has been the focus of fund award for the past five years as shown in Table 6 below, accounting for $9.3 \%$ of the total number of machine tool funds after 2015. Given the fact that individual research funding activity of NSF does not cover the whole research scope of the machine tool domain, we are unable to verify all of the above conclusions derived from the machine tool papers at the global level. However, from the analysis perspective of machine tool funds, we can still prove that cyber-physical system is the focus of research in the machine tool domain, which is consistent with the conclusion obtained by machine tool papers. In addition, another NSF focus in recent years is sustainability, as shown in the table below. The reason is that the critical role of machine tools in the manufacturing industry and the increasing constraints of global environmental resources direct the future development direction of the machine tool industry to be low energy, high efficiency, green and sustainable. According to Topic 14, which is modeled from papers of machine tools in Section 4.1.1, sustainability is also the focus of machine tool research from the perspective of papers. Topic 14 contains high-frequent terms, such as "industry", "safety", "construction", "cost", "economic", "environmental", "sustainability", "enhance", "sustainable" and "costs" et al., representing research topic of sustainability for the machine tool. Some other topics extracted from machine tool papers are also committed to the issue of sustainable development in machine tools. Topic 4 refers to efficiency improvement in machine tools, and Topic 130 focuses on ultrahigh-speed machining. In addition, Topic 7 refers to versatility machine tool and Topic 155 focuses on the reconfigurable machine tool. These technologies are designed to reduce machine tool costs and increase machining efficiency, which further reflects the exploration of promoting sustainable development within machine tools.

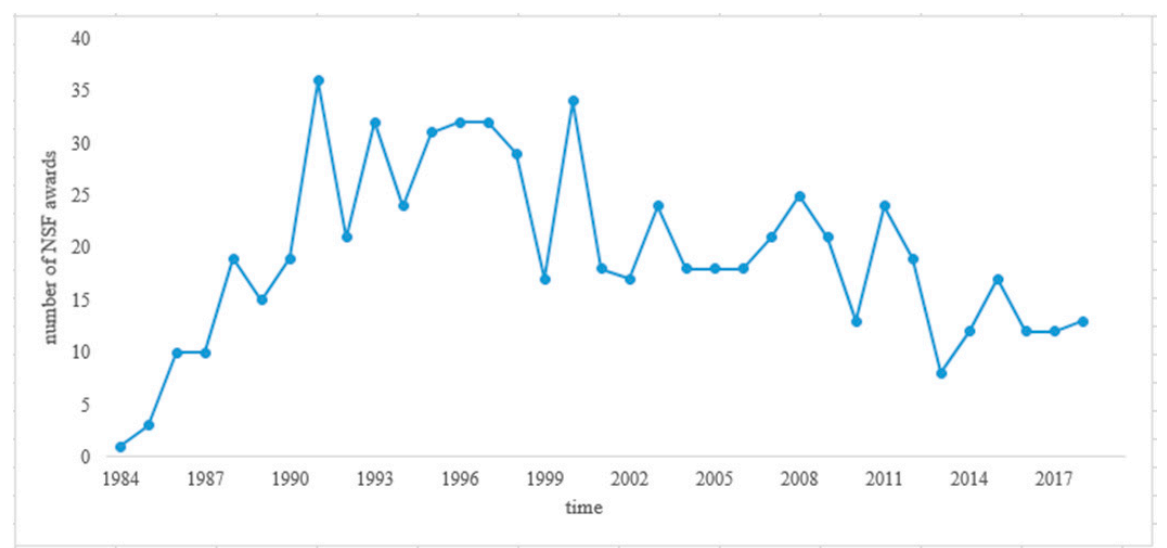

Figure 6. The number over time of machine tool funds granted by NSF. 
Table 6. The funds of machine tool about cyber-physical system and sustainability.

\begin{tabular}{|c|c|c|c|}
\hline Funding Direction & Award Number & Title & Start Date \\
\hline \multirow{5}{*}{$\begin{array}{l}\text { Cyber-Physical } \\
\text { System }\end{array}$} & 1. 1547105 & $\begin{array}{l}\text { EArly-concept Grant for Exploratory Research } \\
\text { (EAGER)/Cybermanufacturing: Just-In-Time } \\
\text { Compilation of Product Manufacturing Data to } \\
\text { Machine Instructions via an Industrial Machine } \\
\text { Operating System }\end{array}$ & $09 / 01 / 2015$ \\
\hline & 2. 1547075 & $\begin{array}{l}\text { EAGER: Cybermanufacturing: Design and } \\
\text { analysis of a cyberphysical systems approach } \\
\text { for custom manufacturing kiosks }\end{array}$ & 09/01/2015 \\
\hline & 3. 1546993 & $\begin{array}{l}\text { EAGER: Cybermanufacturing: Defending Side } \\
\text { Channel Attacks in Cyber-Physical Additive } \\
\text { Layer Manufacturing Systems }\end{array}$ & $10 / 01 / 2015$ \\
\hline & 4. 1646013 & $\begin{array}{l}\text { CPS: Synergy: CNC Process Plan Simulation, } \\
\text { Automation and Optimization }\end{array}$ & 08/01/2016 \\
\hline & 5. 1837146 & $\begin{array}{l}\text { CPS: Small: Mechanical Vibration Based } \\
\text { Prognostic Monitoring of Machinery Health } \\
\text { with Sub-millisecond Accuracy Using } \\
\text { Backscatter Signals }\end{array}$ & $01 / 01 / 2019$ \\
\hline \multirow{4}{*}{ Sustainability } & 1. 1512217 & $\begin{array}{l}\text { UNS: Advancing Environmental Sustainability } \\
\text { through Innovative Design and Operation of } \\
\text { Digital Manufacturing Equipment }\end{array}$ & 05/01/2015 \\
\hline & 2. 1563475 & $\begin{array}{l}\text { Atomized Dielectric-Based Electric Discharge } \\
\text { Machining for Sustainable Manufacturing }\end{array}$ & $04 / 01 / 2016$ \\
\hline & 3. 1635347 & $\begin{array}{l}\text { Eradication of Microbial Contamination in } \\
\text { Metal Working Fluids }\end{array}$ & 09/01/2016 \\
\hline & 4. 1760616 & Eradication of Biofilms in Metal Working Fluids & 09/01/2018 \\
\hline
\end{tabular}

\subsection{Technology Development Analysis of Machine Tool}

Patents have been considered as an important proxy to reflect technological development in the industry. In this section, we analyzed the patents to explore the development characteristics of the technology dimension in machine tools under the environment of new-generation information technology. From the analysis in Section 4.1, the impact of emerging information technologies on machine tool domain is mainly reflected in the integration and application of technologies, such as big data, cloud computing, internet of things, cyber-physic system and artificial intelligence. Based on this observation, we mainly focused on the development of the above technologies in the domain of machine tools. This section focuses on the dimension of technology development and is an extension for Section 4.1. We search the patents of the relevant technologies in machine tools through the keywords that constitute the various technologies in Table 7, below. In this section, we used patent development trajectories and institutional cooperation networks to explore the technology development of machine tools.

\subsubsection{Trajectories of Technologies Development}

We explored the development status of specific technology in the machine tool domain through the method of patent growth trajectory. We counted the number of patents retrieved for each of the emerging technologies in Table 7 by year, as shown in Figure 7 below. It can be observed from Figure 7 that the number of patents of the emerging technologies listed above in the machine tool domain has been increasing through time, indicating that these technologies play an increasingly important role in the practical application of machine tools. Specifically, for big data technology, the phenomenon that the number of affiliated patents in the machine tool domain has been increasing by year since 2000 reflects the accumulation of technologies related to data acquisition, transmission and storage 
and the gradual improvement for digital foundation on machine tools. With the accumulation of more and more data, the efficient analysis of data has become more and more critical. As can be observed from the figure, the application of cloud computing technology in the machine tool domain has made great progress since 2012. In addition, the internet of things technology has been applied in the field of machine tools since 2017 and there has been a significant increase in the number of patents in 2018, indicating that the internet of machine tools is in the early stage of promotion and application. With the landing of big data, cloud computing and internet of things in machine tools, and the gradual improvement of the machine tool information foundation, intelligent technologies, such as machine learning and machine learning-based applications have increased significantly from the year after 2015 , indicating that these intelligent technologies are gradually contributing value in the practical application of machine tools. However, for cyber-physical system (CPS) technology, the number of its patents in the machine tool is very small. In fact, we only retrieved a related patent, indicating that the whole of CPS is still in the research stage and has not been widely used in the machine tool field. Currently, CPS is an emerging direction for machine tool research and more patents will appear in the future.

Table 7. The keywords that constituted the emerging technologies in machine tools.

\begin{tabular}{cl}
\hline Technology & \multicolumn{1}{c}{ Keywords } \\
\hline \multirow{2}{*}{ Big data } & $\begin{array}{l}\text { Big data, data collection, data transmission, transfer protocol, Ethernet, } \\
\text { industrial wireless network, Message Queuing Telemetry Transport (MQTT), } \\
\text { NC-Link, MT-Connect, wireless transmission, distributed platform, Hadoop }\end{array}$ \\
\hline \multirow{2}{*}{ Cloud computing } & $\begin{array}{l}\text { Cloud computing, edge device, edge module, fog calculation, fog end } \\
\text { equipment, cloud platform, cloud service, cloud storage, cloud, industrial } \\
\text { cloud, distributed computations, parallel computing, cloud manufacturing }\end{array}$ \\
\hline Internet of things & Internet of things, industrial, internet of things, industrial internet, IoT, iIoT \\
\hline Cyber-physical systems & Cyber-Physical system, CPS, Digital twins \\
\hline \multirow{2}{*}{$\begin{array}{c}\text { Intelligent methods and } \\
\text { applications }\end{array}$} & $\begin{array}{l}\text { Artificial intelligence, machine learning, logistic regression, support vector } \\
\text { machines, naïv bayes, decision tree, random forest, transfer learning, deep } \\
\text { learning, virtual reality, augmented reality, convolutional neural network, } \\
\text { Recurrent neural network, Restricted Boltzmann machine, supervised } \\
\text { learning, unsupervised learning, neural networks, customized production, } \\
\text { remote monitoring, shared manufacturing, state prediction, state forecasting }\end{array}$ \\
\hline &
\end{tabular}

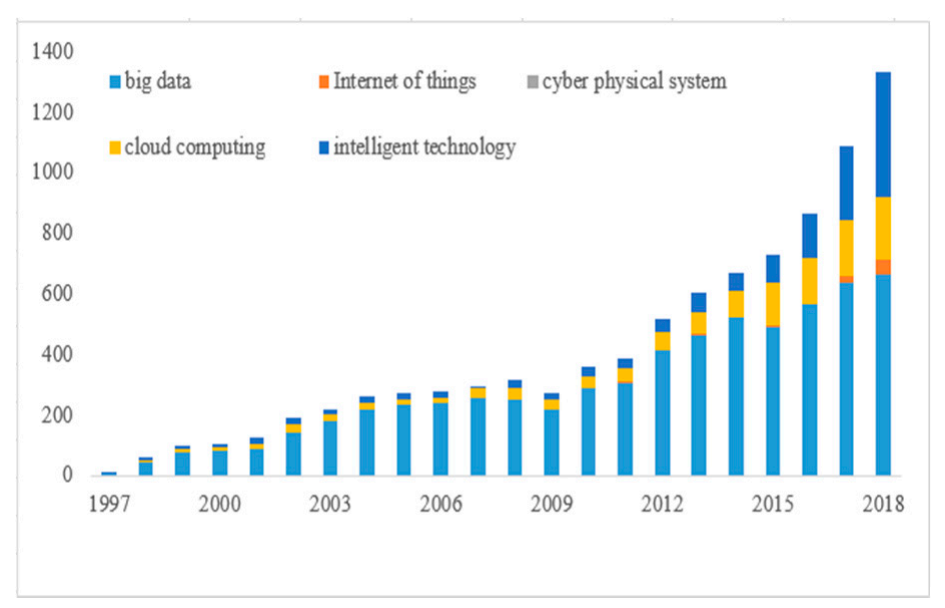

Figure 7. Patent growth trajectory for emerging technologies in the machine tool domain.

Further, we selected a leading organization of machine tool, i.e., FANUC, to count the number of patents of the emerging technologies mentioned above in the machine tool field. As can be observed from Figure 8, the number of patents of big data, cloud computing and technologies related to 
intelligent in FANUC is consistent with the number of the overall machine tools domain. The number of applications for patents related to intelligent technologies has increased significantly in 2017 and 2018 , reflecting FANUC's high attention to machine tool intelligence in recent years. However, it is surprising that FANUC has not laid out IoT technology in the machine tool domain. We conducted in-depth research on this issue and found that FANUC launched the FANUC Intelligent Edge Link and Drive (FIELD) system in 2016 to connect machine tools, robots, peripherals and sensors in automated systems and provided advanced data analysis functions. One reason for not being able to retrieve the FANUC's IoT-related patents in the machine tool domain may be that the company's business has robotics and other fields besides machine tool, and its patent applications of IoT may distribute in other domains. Another reason is that FANUC and Cisco, Rockwell Automation etc. jointly developed the FIELD system, which may reduce its patent application for the internet of things in the field of machine tools.

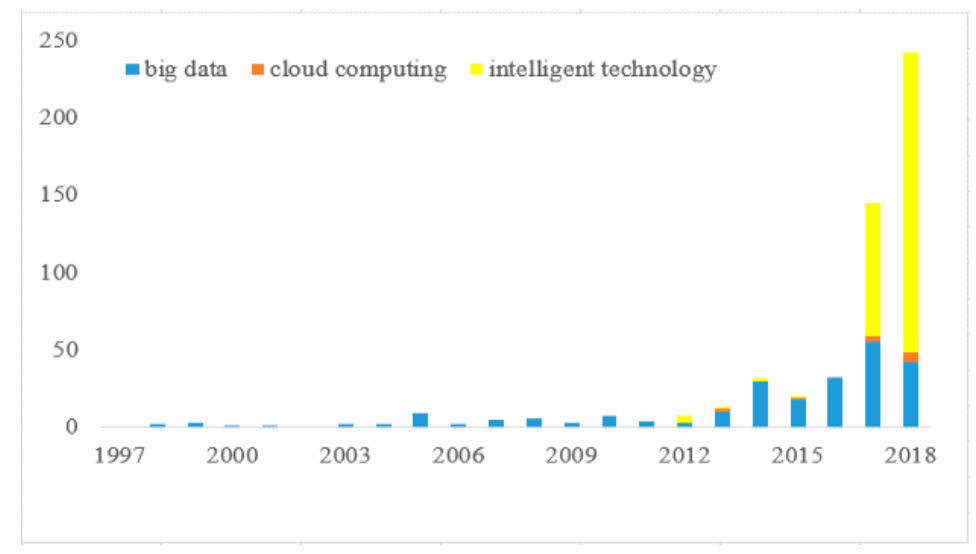

Figure 8. Patent growth trajectory for emerging technologies in FANUC.

Through the above analysis, the conclusions are summarized as follows. (1) Big data and cloud computing have been applied in the machine tool domain and the number of their patents is still increasing in recent years, indicating that these two technologies have begun to land and generate practical value in machine tools. (2) The IoT technology has undergone significant changes in the past two years, indicating that the technology is still in the early stage of promotion and will be the future focus of technology development in the machine tool field. (3) The number of patent applications related to intelligent technologies within the field of machine tools has increased significantly in recent years, indicating that machine tool intelligence is receiving more and more attention in the industry. With the development of artificial intelligence technology and the further improvement of the information basis of machine tool, more researches and development explorations will appear in this direction. (4) Cyber-physics system technology has not yet had abundant patent applications, and the technology is still immature in the domain of machine tools.

\subsubsection{Analysis of Institutional Cooperation Networks}

We analyzed the institutional cooperation network of patents related to the selected emerging technologies within the machine tool. In the experiment, the time span of patents (1997-2018) was divided into two phases and the year of 2010 was set as the demarcation point. The reason lies in that the evolution of emerging technologies in the machine tool domain is accelerating after the year of 2010, which can be observed from Figures 9 and 10. The institutional cooperation network of the patents from 1997 to 2010 is shown in Figure 9 below. In addition, the institutional cooperation network of the patents from 2011 to 2018 is shown in Figure 10. In the two figures, the red node represents the type of company in the domain of information technology. The blue represents the type of company in the traditional machine tool field. Finally, the green represents the type of university institution. 


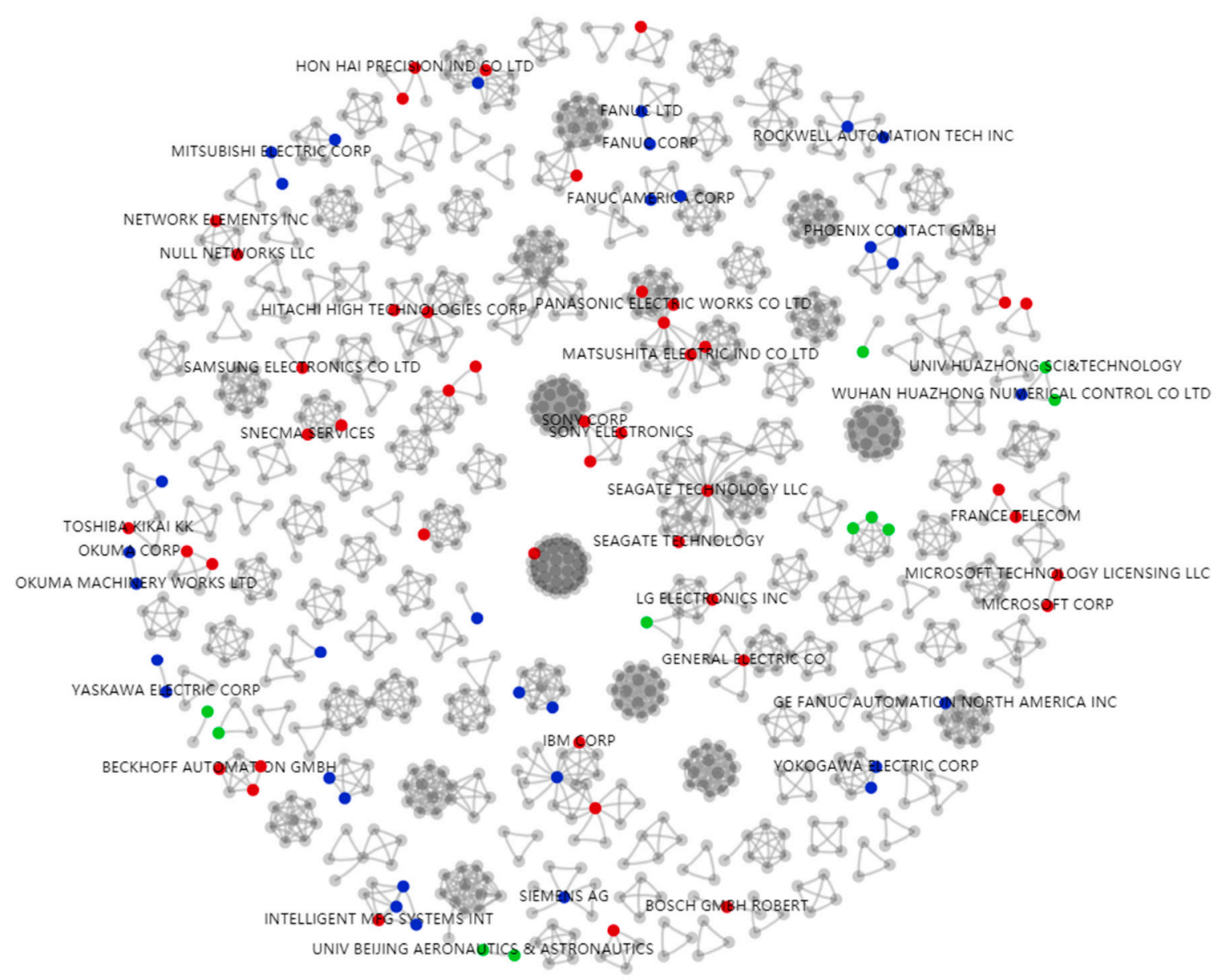

Figure 9. Institutional cooperation network of selected emerging technologies within machine tools (1997-2010).

By comparing the institutional cooperation network of patents within the machine tool domain at two periods, we can observe the following phenomena. Firstly, compared with the period from 1997 to 2010, more and more companies outside the machine tool domain have applied for patents in the domain of machine tools in recent years. These companies include both giant companies in various fields, such as SONY, HITACHI, MATSUSHITA, SAMSUNG, SCHNEIDER, TOSHIBA, Google, GENERAL ELECTRIC CO and emerging artificial intelligence startups like Preferred Network. This indicates that a significant change of machine tools in the era of new-generation information technology is that the cross-border competition in this domain will become the norm in the future. The reason lies in the emerging technologies, such as big data, cloud computing, internet of things and artificial intelligence are enabling technologies and can be widely applied to manufacturing value innovation, production innovation, service innovation and other manufacturing value chains of discrete manufacturing or process manufacturing. The widespread application of the above emerging technologies can empower businesses in different industries to unleash greater technical economic value and lower the cost of technology development. The enabling characteristic makes the cross-border applications of these technologies become possible. This phenomenon is very important, indicating that competition within the machine tool domain in the future will become increasingly fierce. In addition, almost all leading organizations in the machine tool domain have developed patents in these emerging directions in recent years, including not only DMG, FANUC, SIEMENS, OKUMA, but also component companies like MITSUBISHI, YOKOGAWA, OMRON and YASKAWA. This observation shows that the phenomenon of attention change for traditional machine tool enterprises from hardware to software will become more and more common under the influence of the new information technologies. 


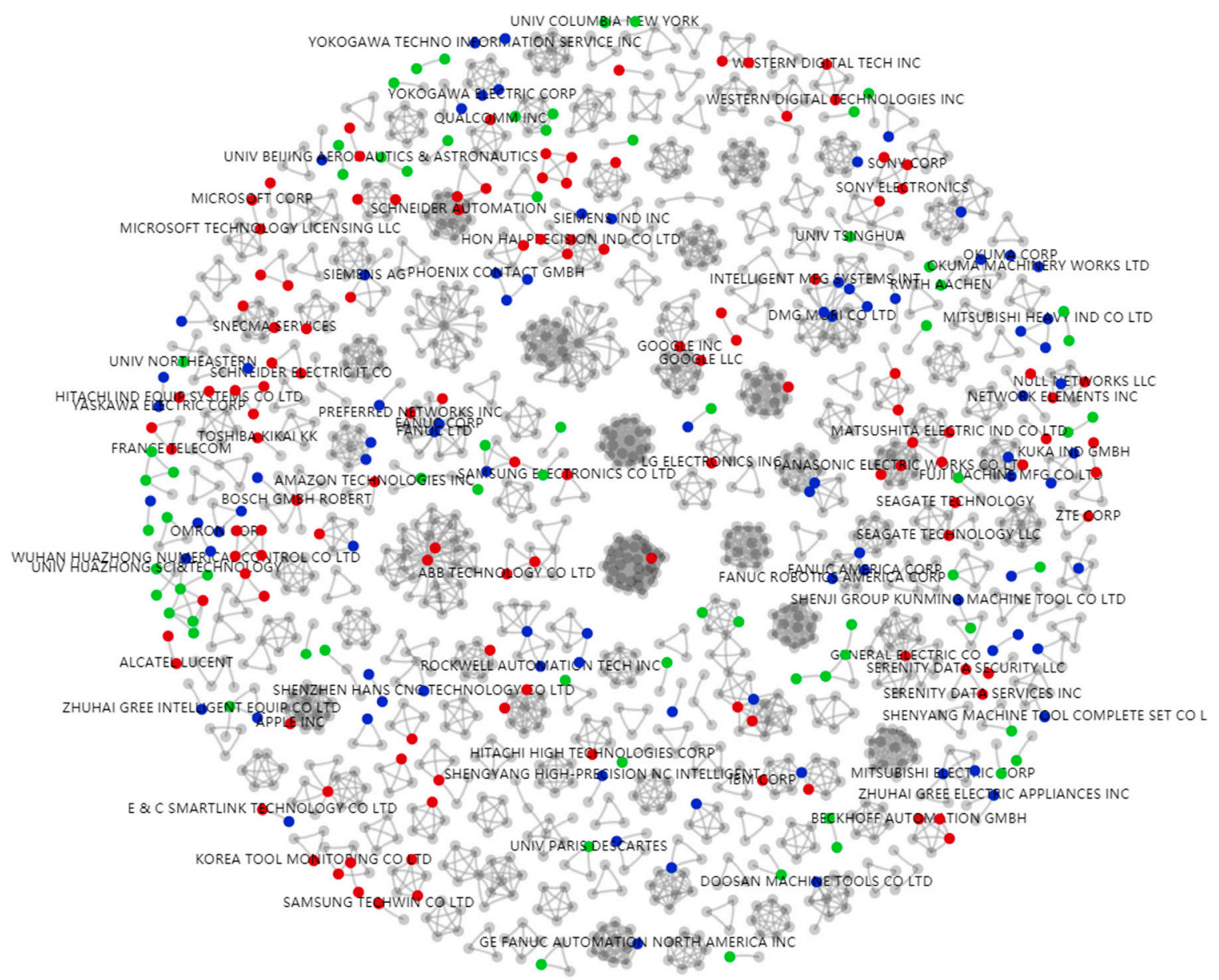

Figure 10. Institutional cooperation network of selected emerging technologies within machine tools (2011-2018).

Meanwhile, based on above observations, cooperation between enterprises within traditional machine tool industry and enterprises outside the machine tool domain may become more and more common. For example, a typical instance in Figure 10 is the collaboration between the Preferred Network and FANUC. Prefer network is an emerging startup of artificial intelligence in Japan. Preferred Network's powerful AI modeling capabilities and FANUC's rich business scenarios, extensive data and abundant domain knowledge form a good complementarity. This cooperation will help different types of companies to take advantage of their respective advantages to quickly bring technology to the market and occupy the market. Further, we can observe from Figures 9 and 10 that more and more university institutions apply for patents about emerging information technology in the machine tool domain, indicating that the university plays a critical role in promoting the integration of the machine tool technology with the emerging information technologies.

From the above analysis, we can summarize two significant changes in the machine tool industry under the influence of the new-generation information technology: (1) The transformation of machine tool enterprises to manufacturing service-oriented organizations; (2) the mutual cooperation of enterprises with different technological backgrounds of machine tools. These two changes constitute an important connotation of the sustainable development of the machine tool industry. Due to the cooperation of different background enterprises will accelerate the landing of emerging technologies and provide a powerful impetus for the future development of the machine tool industry. The transformation of machine tool enterprises into manufacturing service-oriented organizations has expanded the value creation of machine tool enterprises. 


\subsection{Business Model Analysis of Machine Tool Industry}

In this section, we further explored the changes in the business mode of the machine tool industry under the influence of the new-generation information technology. In order to analyze the changes of the industrial mode of the machine tool, we crawled the Google news related to the machine tool business mode released after 2015 for topic modeling analysis. Similar to the topical modeling method of papers in Section 4.1.1, we used manual inspection to optimize the topic modeling results. Upon manual inspection, we set the parameters $\mathrm{K}, \alpha, \beta, I$ to $\mathrm{K}=80, \alpha=0.1, \beta=0.01$ and $I=1000$. After completing the topic modeling for news, we applied the manual interpretation method to check the business modes that focused by machine tool industry in recent years. The extracted business models are shown in Table 8 below.

Table 8. The modeled business concerns of the machine tool industry.

\begin{tabular}{cl}
\hline Topic & \multicolumn{1}{c}{ High-Frequent Terms } \\
\hline Topic 1 & $\begin{array}{l}\text { Intelligence, technologies, learning, reality, information, technology, artificial, augmented, } \\
\text { businesses, part, plc, future, data, virtual, deep }\end{array}$ \\
\hline Topic 2 & $\begin{array}{l}\text { Data, information, process, system, production, control, sensors, monitoring, real-time, } \\
\text { connected, productivity, cloud, sensor, analytics }\end{array}$ \\
\hline Topic 3 & $\begin{array}{l}\text { Machine, monitoring, manufacturing, system, data, Overall Equipment Effectiveness (OEE), } \\
\text { company, production, equipment, shopfloor, data-driven, status, network, downtime, } \\
\text { cloud-based }\end{array}$ \\
\hline Topic 4 & $\begin{array}{l}\text { Equipment, service, customer, downtime, technology, quality, productivity, machine, } \\
\text { monitoring, predictive, reliability, efficiency, increase, remote, preventive }\end{array}$ \\
\hline Topic 5 & $\begin{array}{l}\text { Facility, facilities, energy, central, industry, processing, economic, services, production, } \\
\text { expansion, distribution, e-commerce, cluster, clean, green }\end{array}$ \\
\hline Topic 6 & $\begin{array}{l}\text { Control, machine, CNC, FANUC, app, program, technology, programming, interface, apps, } \\
\text { features, programs, connected, manufacturing, iloT }\end{array}$ \\
\hline Topic 7 & $\begin{array}{l}\text { Device, devices, healthcare, supply, technology, chain, market, health, industry, tool, } \\
\text { technologies, program, competitive, iloT, application }\end{array}$ \\
\hline Topic 8 & $\begin{array}{l}\text { Data, platform, analytics, digital, cloud, applications, platforms, plant, real-time, ecosystem, } \\
\text { PREDIX, twin, transformation, application, cloud-based }\end{array}$ \\
\hline Topic 9 & $\begin{array}{l}\text { IoT, industrial, iloT, things, security, cloud, devices, connected, edge, computing, standards, } \\
\text { applications, connectivity, factory, services }\end{array}$ \\
\hline Topic 10 & $\begin{array}{l}\text { Network, data, wireless, security, machine, system, device, networks, devices, company, server, } \\
\text { programs, technology, computers, miller }\end{array}$ \\
\hline
\end{tabular}

By analyzing the modeling results of the news in Table 8, we can draw the following conclusions. The content of Topic 9 and Topic 10 refers to information about the IoT cloud platform in the machine tool domain. The internet platform based on IoT technology in the machine tool industry enables machine tool enterprises to extend machine tools from the shop floor to the cloud and then use data analysis technologies, such as cloud computing and artificial intelligence to improve the user's insight into plant and production performance. This will promote companies to achieve asset management and data management in a sustainable and economical way to accelerate the process of enterprise intelligence transformation. From the modeling results of these two topics, we can conclude that the business mode based on the IoT cloud platform is one of the concerns of the development of the machine tool industry. The IoT cloud platform of machine tools essentially connects people, processes, data and things through the internet of things technology, and reshapes the value chain of the machine tool industry through the sharing and integration optimization of various resources between intra-enterprise and inter-enterprise. In addition, information about cloud services is reflected in Topic 8, Topic 2, Topic 3 and Topic 4 . With the continuous improvement of the digital foundation of the machine tool domain and the emergence of intelligent technologies, machine tool companies not 
only achieve increased productivity, but also may derive new service mode in addition to machine tool products. The industry mode transformation of the machine tool characterized by intelligent services is another concern of the change of the machine tool industry under the influence of the new-generation information technology, which makes the machine tool enterprises develop from "production-oriented manufacturing" to "manufacturing service-oriented". Machine tool companies can realize value creation based on machine tool services in the future. For example, Topic 2, Topic 3 and Topic 4 reflect that machine tool enterprises establish a cloud platform for monitoring the operation of machine tool equipment based on big data, industrial internet of things and artificial intelligence (Topic 1), which can monitor the operation state of the machine tool and gradually evolve from state monitoring to predictive maintenance. Predictive maintenance of machine tools will also greatly improve the supply chain of the traditional machine tool industry, increasing production efficiency, while further reducing costs (Topic 7). In addition, Topic 6 reflects the application of industrial App in the field of machine tools, indicating that the machine tool App ecosystem may be another important industry paradigm of machine tools. The Industrial App ecosystem is a common enabling technology focused on the generation and utilization of knowledge in the machine tool field, which will greatly enhance the decision-making ability of the machine tool system. The construction of App ecosystem in the machine tool industry revolutionizes the efficiency about generation, utilization, inheritance and accumulation of domain knowledge, and further promotes the precipitation and sharing of knowledge in the machine tool domain. The development of the IoT platform of the machine tool can realize the automatic and repetitive use of knowledge, avoiding the limitations of time and space to increase the value of knowledge further. Through the above analysis, we summarize the emerging industry mode of the machine tool industry in Table 9 below. The change of the machine tool industry mode will also promote the sustainable development capability of the machine tool industry and make the future development of the machine tool industry become more and more clean and green. Sustainability will become a focus of the future development of the machine tool industry (Topic 5).

Table 9. Emerging business mode in the machine tool industry.

\begin{tabular}{ccc}
\hline \multirow{2}{*}{$\begin{array}{c}\text { Cloud-based IoT Ecosystem } \\
\text { of Machine Tool }\end{array}$} & IoT Cloud Platform of Machine Tool & Topic 9, Topic 10 \\
\cline { 2 - 3 } & Cloud Service Mode & Topic 8, Topic 2, Topic 3, Topic 4 \\
\cline { 2 - 3 } & App Ecosystem of Machine Tool & Topic 6 \\
\hline
\end{tabular}

\subsection{Discussion}

Experimental results above show that new-generation information technology is triggering profound changes in the research system, technology development and industry of machine tools. In this section, we made a deep joint analysis of machine tool development, merging multi-perspectives, such as research, technology development, and business. From the joint perspective, we can observe the obvious transfer phenomenon of emerging changes in various technical activities of machine tools. Firstly, as can be seen from investigation for papers and funds in Section 4.1, emerging technologies, such as big data, cloud computing, internet of Things, cyber-physics systems and deep learning etc. have become the focuses and important trends of machine tool research. The combination of these emerging technologies and machine tool research is highlighted in improving failure prediction and state monitoring for machine tools and components. The reason lies in that the accumulation of big data on machine tools, and the application of complex algorithms, such as deep learning, makes the related research gradually develop toward predictive maintenance. With the maturity of these intelligent technologies and applications, the performance and operating efficiency of machine tool equipment will be greatly improved which makes the practical landing of these technologies become possible. Then, in view of the potential improvement space for these emerging technologies to the practical performance of machine tools, the machine tool industry has also begun to accelerate the layout of the above emerging technologies. Machine tool companies represented by FUNAC have strengthened their 
investment in technologies, such as big data, cloud computing and machine learning in recent years. In view of the enabling characteristics of cloud computing, internet of things and artificial intelligence, not only the traditional machine tool giants are focusing on the layout, but many non-machine tool companies are also stepping up their technical investment in these directions, resulting in the further formation of cross-border integration in the machine tool field. The competition in the machine tool domain will be increased further, which will also promote the cooperation between enterprises with different technical backgrounds. The emerging technologies generated by the integration of the machine tool domain and the new-generation information technologies laid the technical condition for the transformation of the machine tool industry mode. Finally, from the analysis of Section 4.3 for news after the year of 2015, the cloud-based IoT ecosystem of the machine tool is the core concern of the industry mode in machine tools. The cloud-based IoT ecosystem of the machine tool is embodied in the IoT cloud platform of machine tool, cloud service mode and App ecosystem of machine tools. This marks the machine tool industry is changing from the traditional manufacturing industry to service-oriented manufacturing. The above analysis reflects the logic that the impact of the new-generation information technology on the machine tool field is gradually transferring from the research to the industry. This is an important conclusion which can help us make predictions about the future development of machine tools.

In the future, the trend of interdisciplinary integration in the machine tool field will become more and more significant, which will make the machine tool domain develop towards the intelligent direction gradually. For specific technology, CPS will be more critical in the future development of the machine tool in light of CPS is attracting more and more attention in machine tool research, but has not yet had abundant patent applications. For technology development in machine tools, cross-border integration will become the future norm with the research maturity of emerging technologies. The reason lies in the enabling characteristic of these technologies. As for the industry of machine tool, the construction of the cloud platform ecosystem will become the focus of competition in the future. These trends will promote the machine tool industry to gain new competitive advantages and promote the development of the global manufacturing industry into a new stage.

\section{Exploring Sustainability for Future Machine Tool Industry}

The machine tool is the ubiquitous instrument in the manufacturing industry and virtually everything in the industry is manufactured using it. However, the processing process of the machine tool is accompanied by the consumption of a large amount of resource and discharge of environmental pollutants. With the current tightening constraints of resource environment, it is critical to explore sustainability implications for future machine tool domain. The above analysis shows that with the advent of the Fourth Industrial Revolution, many emerging changes and new trends contained in the machine tool domain. The above researches on the emerging developments and future trends in the machine tool domain can provide inspiration for the direction of sustainable development in machine tools. In this section, we explore the sustainability implications of the machine tool domain based on the above studies.

Firstly, the introduction of emerging machine tool technologies to transform the traditional technologies in the machine tool domain and the development of green machine tools that save energy, reduce consumption and reduce environmental pollution is one of the key ways for the sustainable development of the machine tool industry in the future. The development of emerging technologies in the machine tool domain has laid the technical foundation for the maturity of green machine tools. The collection and analysis of machine tool big data is beneficial to record and optimize the process of the whole life cycle of the machine tool. The accumulation and mining of abundant machine tool big data can contribute optimizing the machine tool design and improving intergenerational evolution of the machine tool. This helps realize machine tool design that uses the least resource consumption and has the least environmental impact. In addition, the analysis of machine tool big data can realize real-time monitoring of machine tool processing status and predictive maintenance of 
equipment. Based on these, the machine tool can optimize the machining process to improve machining efficiency, reduce energy consumption and improve raw material utilization. The development of cloud computing technology and artificial intelligence in machine tools provides a method for analyzing big data of machine tools and enables the machine tool to have the ability of self-knowledge generation and adaptive control, which will greatly improve the performance of the machine tool. The machine tool IoT technology promotes the accumulation of machine tool big data and the collaborative control of the machine tool group. Combined with the CPS technology of machine tool, it further greatly improves the management ability and the processing efficiency of the machine tool group. Moreover, based on the IoT technology in machine tools, the free sharing and reuse of knowledge between machine tools can be realized, which greatly accelerates the continuous evolution of the machine tool industry. The integration of the above emerging technologies has increased the level of intelligence of machine tools and promoted the development of machine tools towards green machine tools.

The transformation of the traditional machine tool manufacturing mode by the cloud-based machine tool IoT ecosystem and the resulting transformation of machine tool enterprises into manufacturing services is another key way for the sustainable development of the machine tool industry. A large number of raw materials are consumed in the machine tool manufacturing process, and saving raw materials is a factor that must be considered in the sustainable development of machine tools. Machine tool IoT ecosystem can greatly improve the management ability of machine tools both in time and space dimensions. Intelligent services based on the IoT ecosystem of the machine tool, such as equipment fault prediction, real-time monitoring of machining status and remote maintenance can greatly improve the working efficiency of the machine tool and significantly reduce the risk of component failure, thus avoiding waste of raw materials, due to failure. In addition, intelligent services based on the machine tool IoT ecosystem can improve the management of the raw material supply chain of machine tool components, reduce inventory and avoid waste of raw materials.

Machine tool remanufacturing technology is another way to achieve sustainable development in the machine tool industry. Comprehensive remanufacturing of old machine tools, effectively recovering and improving its performance and functions, and improving the control of its machining accuracy can greatly save costs compared with the purchase of new machine tools of the same performance level. The key challenge of machine tool remanufacturing is the state prediction of core components in machine tools. Accurate prediction of the state of machine tool components is a prerequisite for component reuse, which can greatly reduce the cost of machine tool remanufacturing. The integration of big data technology and artificial intelligence technology makes it possible to predict the failure of machine components and predict the state, thus promoting the sustainable development of machine tool remanufacturing.

In addition, the machining process of the machine tool requires a large amount of cutting fluid and coolant, which is a root source of environmental pollution. It can be seen from Table 6 in Section 4.1.4 that the study on the sustainable use of machine cutting fluid is the focus of current research in the field of machine tools. In the future, the recyclability technology of the machine tool cutting fluids and coolants should be one of the key ways for the sustainable development of the machine tool industry.

At the key nodes in the development of the machine tool industry, making accurate judgments on development opportunities and implementing correct strategies have a decisive impact on the development of the machine tool industry. And this will also be conducive to the sustainable development of machine tools. The interdisciplinary trend of machine tool also indicates the complexity in machine tool development. The collaboration of technology, society and government will be critical to the future development of machine tools. The above findings may offer important implications for systematic and nuanced policies in the machine tool domain. For researchers, more attention can be paid on the combination of big data, artificial intelligence, CPS and machine tools domain. In addition, researchers in the machine tool field should focus on the recyclability technology of machine tool cutting fluids and coolants. For machine tool enterprises, they should pay attention to the improvement of the internet of things and cloud computing technology for enterprise business. 
Enterprises also should attach importance to the collection of machine tool big data, data-driven knowledge mining and the transformation towards manufacturing service-oriented organizations. For the machine tool industry, it is necessary to organize and implement a standard system, including industrial information security, interconnection and communication. Finally, in view of the basic role of the machine tool industry in manufacturing, national policies should be developed at various national levels to encourage collaborative innovation in the industry, academia and research in the international arena. Relevant laws and regulations should also be enacted to ensure the security of big data and the internet of things platform in the machine tool field.

\section{Conclusions}

The complex intrinsic heterogeneity of the machine tool discipline and the dimension complexity of development in machine tools make the exploration of the evolution in machine tools become a challenging task. In this paper, we proposed an integrating framework to solve the above challenge by analyzing multi-source literature. The proposed framework consists of machine learning, bibliometric, patent analysis, and trend analysis methods. The advantage of the proposed framework is that it has the capabilities of semantic, time dynamic and multi-dimensional analysis. The main contributions of the paper are as follows.

Firstly, the development of the machine tool domain in a complex environment is analyzed. The main findings are as follows. Firstly, through the analysis of papers and funds for machine tools, we find that big data, cloud computing, internet of things, cyber-physical system, machine learning and deep learning have become the focuses and important research trends of machine tool research. Secondly, through the analysis of the machine tool patents, we find that these emerging technologies have been applied in practical applications of machine tools in recent years to generate value, except for cyber-physical system. Not only the traditional machine tool giants are focusing on the layout of these emerging technologies, but many non-machine tool companies are also stepping up their technical investment in these directions, leading to the further formation of cross-border integration in the machine tool field. We also observe that universities have played an increasingly important role in the application transformation of emerging technologies in the machine tool industry. Finally, it is found that the business mode of the machine tool has changed greatly based on the analysis of machine tool news. The cloud-based IoT ecosystem of the machine tool is the core characteristic of the development mode of the machine tool industry, indicating the machine tool industry is moving from the traditional manufacturing industry to service-oriented manufacturing industry.

Secondly, we perform a systematic analysis of multi-source scientific literature related to machine tool to explore its development from the multi-view perspectives of research, technology development and business mode. Through the multi-dimensional analysis of the development, this paper systematically clarified the roadmap of the impact of the new-generation information technology on the machine tool domain. We find that the impact of external information technologies on the machine tool field is gradually transferring from research, technology development to industrial mode. Machine tool research and technology development constitute the cornerstone of the industry mode change in machine tools. Based on the above analysis, we explore the sustainability implications for future machine tool industry.

Finally, we propose a new research framework with the capabilities of semantic, temporal dynamics and multi-perspective analysis. The proposed framework not only provides effective support for the analysis of development studies in the machine tool field, but also has certain versatility. Especially for the evolution of traditional domains influenced by the new-generation information technology, our proposed framework also applies.

The limitations of this paper are as follows. Our work aims to use quantitative analysis methods like machine learning to study the development of machine tools. The future integration of expert domain knowledge to combine the analysis of qualitative and quantitative is of significance for predicting the future development of machine tools. In addition, the paper focuses on the impact of the 
new-generation information technology on the machine tool field. Developments of many traditional technologies in machine tools have not been analyzed. The analysis of these technologies will facilitate a more comprehensive exploration of the development of this domain.

Author Contributions: Funding acquisition, Y.Z.; Methodology, K.Z., L.L.; Project administration, J.C.; Validation, Z.C.; Visualization, L.Y.; Writing—original draft, K.Z.; Writing—review and editing, Y.Z., Y.L. and K.Z.

Funding: This research was funded by the National Natural Science Foundation of China (Nos. 91646102, L1824039, L1724034, L1724026, L1624045, L1524015, 71203117), the MOE (Ministry of Education in China) Project of Humanities and Social Sciences (16JDGC011), the Construction Project of China Knowledge Center for Engineering Sciences and Technology (No. CKCEST-2019-2-13), the UK-China Industry Academia Partnership Program (UK-CIAPP/260), Tsinghua University Project of Volvo-supported Green Economy and Sustainable Development (20153000181), and Tsinghua Initiative Research Project (2016THZW).

Conflicts of Interest: The authors declare no conflict of interest.

\section{Appendix A}

Table A1. Topic modeling results of machine tool papers.

\begin{tabular}{|c|c|c|}
\hline Meaning & Topic & High-Frequent Terms \\
\hline Fuzzy system & Topic 1 & $\begin{array}{l}\text { Fuzzy, system, logic, rules, inference, adaptive, ANFIS, rule, } \\
\text { neuro-fuzzy, performance, input, learning, systems, } \\
\text { appropriate, function }\end{array}$ \\
\hline Industrial robot & Topic 2 & $\begin{array}{l}\text { Robot, industrial, robotic, system, control, purpose, task, trajectory, arm, } \\
\text { flexibility, mobile, perform, robotics, flexible, human-robot }\end{array}$ \\
\hline $\begin{array}{l}\text { Joints dynamic } \\
\text { modeling }\end{array}$ & Topic 3 & $\begin{array}{l}\text { Joint, assembly, tool, dynamics, model, coupling, point, dynamic, } \\
\text { modeling, modeled, interface, beam, interfaces, rigid, response }\end{array}$ \\
\hline $\begin{array}{l}\text { Efficiency } \\
\text { improvement }\end{array}$ & Topic 4 & $\begin{array}{l}\text { Method, calculation, effective, accurate, accurately, experiment, realize, } \\
\text { combination, improve, effectiveness, fast, feasible, efficiency, } \\
\text { optimizing, theory }\end{array}$ \\
\hline $\begin{array}{l}\text { Dynamic response } \\
\text { analysis }\end{array}$ & Topic 5 & $\begin{array}{l}\text { Dynamic, model, stiffness, system, static, response, dynamics, effects, } \\
\text { coupling, nonlinear, coupled, damping, analysis, } \\
\text { time-varying, influence }\end{array}$ \\
\hline High speed spindle & Topic 6 & $\begin{array}{l}\text { Spindle, high-speed, spindles, high, speeds, rotating, motorized, system, } \\
\text { radial, rotational, axial, rotation, displacement, centrifugal, effects }\end{array}$ \\
\hline $\begin{array}{l}\text { Versatility machine } \\
\text { tool }\end{array}$ & Topic 7 & $\begin{array}{l}\text { Machine, tools, tool, parts, precise, mapping, calculate, rapidly, } \\
\text { versatile, acquire, repeatable, versatility, institute, VMS, structured }\end{array}$ \\
\hline $\begin{array}{l}\text { Production } \\
\text { management }\end{array}$ & Topic 8 & $\begin{array}{l}\text { Manufacturing, management, production, information, industry, } \\
\text { market, case, competitive, manufacturers, RFID, enterprises, supply, } \\
\text { chain, resource, costs }\end{array}$ \\
\hline $\begin{array}{l}\text { Joints stiffness } \\
\text { theory }\end{array}$ & Topic 9 & $\begin{array}{l}\text { Contact, deformation, elastic, stiffness, theory, pressure, area, force, } \\
\text { influence, distribution, displacement, load, theoretical, normal, plastic }\end{array}$ \\
\hline $\begin{array}{l}\text { Non-linear } \\
\text { modeling }\end{array}$ & Topic 10 & $\begin{array}{l}\text { Model, modelling, process, performance, forecasting, data, non-linear, } \\
\text { empirical, physical, estimate, situations, polynomial, mathematical, } \\
\text { data-driven, gradient-based }\end{array}$ \\
\hline $\begin{array}{l}\text { Vibration signal } \\
\text { analysis }\end{array}$ & Topic 11 & $\begin{array}{l}\text { Mode, method, decomposition, signal, empirical, signals, EMD, } \\
\text { singular, intrinsic, entropy, analysis, feature, vibration, } \\
\text { local, decomposed }\end{array}$ \\
\hline $\begin{array}{l}\text { Tolerance design } \\
\text { method }\end{array}$ & Topic 12 & $\begin{array}{l}\text { Method, tolerance, equations, equation, tolerances, parametric, design, } \\
\text { quadratic, differential, non-linear, equivalent, solving, initial, } \\
\text { dimensions, partial }\end{array}$ \\
\hline Online monitoring & Topic 13 & $\begin{array}{l}\text { Sensors, monitoring, sensing, system, online, fusion, measurements, } \\
\text { wireless, information, signals, in-process, installed, sensory, } \\
\text { monitor, integration }\end{array}$ \\
\hline
\end{tabular}


Table A1. Cont.

\begin{tabular}{|c|c|c|}
\hline Meaning & Topic & High-Frequent Terms \\
\hline $\begin{array}{l}\text { Development of } \\
\text { machine tool }\end{array}$ & Topic 14 & $\begin{array}{l}\text { Industry, safety, construction, cost, risk, improvement, case, economic, } \\
\text { environmental, sustainability, enhance, care, sustainable, health, costs }\end{array}$ \\
\hline $\begin{array}{l}\text { Rapid prototyping } \\
\text { technology }\end{array}$ & Topic 15 & $\begin{array}{l}\text { Rapid, prototyping, tooling, metal, manufacturing, casting, slicing, part, } \\
\text { deposition, CNC, prototype, processes, mould, material, slice }\end{array}$ \\
\hline Feed servo system & Topic 16 & $\begin{array}{l}\text { Feed, rate, drive, rates, drives, high, servo, machining, machine, } \\
\text { high-speed, tool, cycle, speeds, accurately, torque }\end{array}$ \\
\hline $\begin{array}{l}\text { Bearing fault } \\
\text { diagnosis }\end{array}$ & Topic 17 & $\begin{array}{l}\text { Signal, noise, signals, method, fault, bearing, weak, adaptive, ratio, } \\
\text { filter, resonance, effectiveness, impulses, components, periodic }\end{array}$ \\
\hline Part machining & Topic 18 & $\begin{array}{l}\text { Part, parts, set-up, machining, machined, dimensions, volumes, } \\
\text { grouping, manufactured, modelled, set-ups, determines, three-axis, } \\
\text { define, ensuring }\end{array}$ \\
\hline Response analysis & Topic 19 & $\begin{array}{l}\text { Response, parameters, analysis, design, models, process, mathematical, } \\
\text { RSM, responses, values, factor, variance, surface, model, variables }\end{array}$ \\
\hline $\begin{array}{l}\text { Intelligent control } \\
\text { system }\end{array}$ & Topic 20 & $\begin{array}{l}\text { Intelligent, system, support, intelligence, control, autonomous, agent, } \\
\text { decision, artificial, distributed, architecture, decision-making, } \\
\text { autonomously, evolution, self-learning }\end{array}$ \\
\hline Material properties & Topic 21 & $\begin{array}{l}\text { Layer, surface, thickness, layers, machined, recast, steel, material, } \\
\text { materials, properties, resistance, higher, hardness, high, lower }\end{array}$ \\
\hline Motion control & Topic 22 & $\begin{array}{l}\text { Position, velocity, moving, desired, motion, acceleration, maximum, } \\
\text { positions, commands, follower, generate, track, computed, } \\
\text { move, command }\end{array}$ \\
\hline $\begin{array}{l}\text { Multi-objective } \\
\text { optimization } \\
\text { algorithm }\end{array}$ & Topic 23 & $\begin{array}{l}\text { Optimization, algorithm, genetic, optimal, parameters, algorithms, } \\
\text { multi-objective, objectives, optimized, problem, optimize, evolutionary, } \\
\text { performance, evolution, search }\end{array}$ \\
\hline Genetic algorithm & Topic 24 & $\begin{array}{l}\text { Algorithm, genetic, local, search, problem, global, modified, operator, } \\
\text { convergence, solution, optimal, initial, algorithms, solve, space }\end{array}$ \\
\hline Profile control & Topic 25 & $\begin{array}{l}\text { Measuring, measurement, inspection, coordinate, probe, measured, } \\
\text { accuracy, machine, system, CMM, data, model, on-machine, } \\
\text { error, profile }\end{array}$ \\
\hline $\begin{array}{l}\text { CNC machine } \\
\text { center }\end{array}$ & Topic 26 & $\begin{array}{l}\text { Machining, center, vertical, CMC, centers, piece, horizontal, center, test, } \\
\text { analyzed, identifying, relation, evaluation, disadvantages, direction }\end{array}$ \\
\hline $\begin{array}{l}\text { Robust control of } \\
\text { machine tool }\end{array}$ & Topic 27 & $\begin{array}{l}\text { Robust, uncertainty, robustness, effective, parametric, method, } \\
\text { conditions, model, uncertain, complexity, task, deal, handle, } \\
\text { parameter, performance }\end{array}$ \\
\hline Process planning & Topic 28 & $\begin{array}{l}\text { Process, planning, manufacturing, plan, plans, machining, operations, } \\
\text { CAPP, operation, part, sequence, environment, selection, tools, } \\
\text { computer-aided }\end{array}$ \\
\hline Evaluation method & Topic 29 & $\begin{array}{l}\text { Decision, process, selection, evaluation, criteria, problem, fuzzy, } \\
\text { decision-making, analysis, similarity, alternative, theory, weights, } \\
\text { AHP, hierarchy }\end{array}$ \\
\hline $\begin{array}{l}\text { Cost management } \\
\text { of machine tool }\end{array}$ & Topic 30 & $\begin{array}{l}\text { Production, cost, manufacturing, demand, line, productivity, batch, } \\
\text { product, high, capacity, reduction, economic, lifespan, } \\
\text { economical, customization }\end{array}$ \\
\hline Polishing process & Topic 31 & $\begin{array}{l}\text { Polishing, surface, abrasive, diamond, tool, process, optical, aspheric, } \\
\text { freeform, mirror, workpiece, quality, precision, lens, roughness }\end{array}$ \\
\hline $\begin{array}{l}\text { Gear of machine } \\
\text { tool }\end{array}$ & Topic 32 & $\begin{array}{l}\text { Tooth, modification, method, bevel, gear, contact, machine, modified, } \\
\text { settings, spiral, hypoid, machine-tool, pinion, profile, transmission }\end{array}$ \\
\hline
\end{tabular}


Table A1. Cont.

\begin{tabular}{|c|c|c|}
\hline Meaning & Topic & High-Frequent Terms \\
\hline $\begin{array}{l}\text { Model calibration } \\
\text { of NT }\end{array}$ & Topic 33 & $\begin{array}{l}\text { Mechanism, method, identification, model, calibration, theoretical, } \\
\text { parameter, simulation, experiment, effective, accuracy, decoupling, } \\
\text { coupling, identifiability, kinematical }\end{array}$ \\
\hline Neural network & Topic 34 & $\begin{array}{l}\text { Network, neural, networks, learning, training, radial, function, } \\
\text { propagation, RBF, prediction, trained, weights, conditions, predict, } \\
\text { back-propagation }\end{array}$ \\
\hline $\begin{array}{l}\text { Frequency domain } \\
\text { analysis }\end{array}$ & Topic 35 & $\begin{array}{l}\text { Frequency, domain, analysis, spectrum, signal, spectral, components, } \\
\text { envelope, frequencies, characteristic, phase, synchronous, bands, } \\
\text { presence, band }\end{array}$ \\
\hline $\begin{array}{l}\text { Adaptive control of } \\
\text { machine tool }\end{array}$ & Topic 36 & $\begin{array}{l}\text { Control, controller, adaptive, system, PID, gain, performance, tuning, } \\
\text { process, servo, simulation, stability, robustness, dynamics, self-tuning }\end{array}$ \\
\hline Loading analysis & Topic 37 & $\begin{array}{l}\text { Load, operating, condition, measured, speeds, running, operation, } \\
\text { fluctuating, changes, time-varying, variable, loading, simulated, } \\
\text { steady-state, response }\end{array}$ \\
\hline $\begin{array}{l}\text { Efficiency } \\
\text { improvement }\end{array}$ & Topic 38 & $\begin{array}{l}\text { Increase, effect, decrease, improve, efficiency, effects, reduced, negative, } \\
\text { productivity, improvement, improves, influence, trend, } \\
\text { dramatically, properties }\end{array}$ \\
\hline $\begin{array}{l}\text { Performance } \\
\text { optimization }\end{array}$ & Topic 39 & $\begin{array}{l}\text { Optimization, optimal, constraints, cost, maximum, function, optimum, } \\
\text { minimize, optimized, constraint, criterion, value, problem, } \\
\text { effectiveness, productivity }\end{array}$ \\
\hline $\begin{array}{l}\text { Protocol and } \\
\text { security of IoT }\end{array}$ & Topic 40 & $\begin{array}{l}\text { Iot, devices, internet, protocol, security, COAP, things, protocols, } \\
\text { communication, networks, web, network, mobile, message, MQTT }\end{array}$ \\
\hline Impedance analysis & Topic 41 & $\begin{array}{l}\text { Variation, effect, changes, analyzed, dimensional, reduction, effective, } \\
\text { space, causes, propagation, analysis, evaluation, manifold, } \\
\text { inherent, impedance }\end{array}$ \\
\hline Guideways friction & Topic 42 & $\begin{array}{l}\text { Friction, coefficient, effects, sliding, yarn, velocity, mechanical, frictional, } \\
\text { properties, guideways, rotor, ratios, tribological, reliable, analysis }\end{array}$ \\
\hline $\begin{array}{l}\text { Performance } \\
\text { improvement }\end{array}$ & Topic 43 & $\begin{array}{l}\text { Performance, improve, evaluation, measures, effective, enhance, } \\
\text { improvement, superior, comparative, high, excellent, action, } \\
\text { high-performance, analyzed, modifications }\end{array}$ \\
\hline $\begin{array}{l}\text { Kinematic analysis } \\
\text { of machine tool }\end{array}$ & Topic 44 & $\begin{array}{l}\text { Parallel, kinematic, workspace, stiffness, mechanisms, machine, } \\
\text { mechanism, design, kinematics, synthesis, redundant, PKM, } \\
\text { performance, redundancy, structure }\end{array}$ \\
\hline $\begin{array}{l}\text { Material removal } \\
\text { rate }\end{array}$ & Topic 45 & $\begin{array}{l}\text { Material, removal, rate, process, MRR, parameters, metal, volume, tool, } \\
\text { effect, maximum, higher, predicted, PMND-EDM, optimizing }\end{array}$ \\
\hline $\begin{array}{l}\text { Ball screw feed } \\
\text { system }\end{array}$ & Topic 46 & $\begin{array}{l}\text { Ball, screw, system, linear, machine, positioning, accuracy, drive, slide, } \\
\text { moving, guideway, preload, roller, ball-screw, high-precision }\end{array}$ \\
\hline $\begin{array}{l}\text { Interpolation } \\
\text { algorithm }\end{array}$ & Topic 47 & $\begin{array}{l}\text { Curve, interpolation, NURBS, curves, points, b-spline, parametric, } \\
\text { interpolator, spline, algorithm, real-time, non-uniform, CNC, line, fitting }\end{array}$ \\
\hline $\begin{array}{l}\text { Production } \\
\text { scheduling }\end{array}$ & Topic 48 & $\begin{array}{l}\text { Scheduling, flexible, manufacturing, machine, operation, production, } \\
\text { capacity, allocation, tools, flexibility, processing, planning, resources, } \\
\text { schedule, assignment }\end{array}$ \\
\hline Surface quality & Topic 49 & $\begin{array}{l}\text { Surface, machined, quality, roughness, topography, process, influence, } \\
\text { workpiece, integrity, parameters, effect, electron, scanning, } \\
\text { analyzed, mechanism }\end{array}$ \\
\hline $\begin{array}{l}\text { Parameters } \\
\text { optimization }\end{array}$ & Topic 50 & $\begin{array}{l}\text { Parameters, analysis, optimal, grey, orthogonal, performance, relational, } \\
\text { method, process, ratio, variance, optimization, rate, } \\
\text { combination, optimum }\end{array}$ \\
\hline
\end{tabular}


Table A1. Cont.

\begin{tabular}{|c|c|c|}
\hline Meaning & Topic & High-Frequent Terms \\
\hline $\begin{array}{l}\text { Stability theory of } \\
\text { machine tool }\end{array}$ & Topic 51 & $\begin{array}{l}\text { Phase, stability, delay, system, periodic, nonlinear, theory, numerical, } \\
\text { equation, stable, differential, regenerative, dynamics, linear, vibrations }\end{array}$ \\
\hline $\begin{array}{l}\text { Particle swarm } \\
\text { optimization }\end{array}$ & Topic 52 & $\begin{array}{l}\text { Optimization, particle, parameters, swarm, PSO, optimize, } \\
\text { performance, model, improve, algorithm, optimizing, particles, } \\
\text { multi-objective, improved, optimal }\end{array}$ \\
\hline $\begin{array}{l}\text { Cutting machining } \\
\text { of machine tool }\end{array}$ & Topic 53 & $\begin{array}{l}\text { Chip, cutting, formation, tool, thickness, forces, edge, process, } \\
\text { machining, shear, conditions, orthogonal, interface, zone, tool-chip }\end{array}$ \\
\hline $\begin{array}{l}\text { Automatic tool } \\
\text { change algorithm }\end{array}$ & Topic 54 & $\begin{array}{l}\text { Algorithm, efficient, automatic, discrete, fast, effective, cycles, suitable, } \\
\text { matching, efficiency, automatically, slow, ATC, } \\
\text { time-consuming, manually }\end{array}$ \\
\hline $\begin{array}{l}\text { Process sequence } \\
\text { optimization }\end{array}$ & Topic 55 & $\begin{array}{l}\text { Optimization, operation, constraints, line, sequence, graph, case, } \\
\text { balancing, feasible, optimized, precedence, analyzed, transfer, } \\
\text { cycle, machining }\end{array}$ \\
\hline $\begin{array}{l}\text { Reliability } \\
\text { technology }\end{array}$ & Topic 56 & $\begin{array}{l}\text { Reliability, failure, analysis, degradation, method, assessment, modes, } \\
\text { failures, allocation, case, information, field, mode, } \\
\text { comprehensive, function }\end{array}$ \\
\hline Internet of things & Topic 57 & $\begin{array}{l}\text { Energy, wireless, iot, devices, access, channel, transmission, network, } \\
\text { consumption, communication, networks, performance, internet, } \\
\text { things, power }\end{array}$ \\
\hline Signal analysis & Topic 58 & $\begin{array}{l}\text { Wavelet, transform, signals, signal, vibration, time-frequency, analysis, } \\
\text { fourier, discrete, feature, processing, technique, fast, features, extraction }\end{array}$ \\
\hline $\begin{array}{l}\text { Electric discharge } \\
\text { machining }\end{array}$ & Topic 59 & $\begin{array}{l}\text { Electrode, EDM, machining, discharge, electrical, material, process, } \\
\text { removal, wear, surface, MRR, electrodes, powder, gap, pulse }\end{array}$ \\
\hline $\begin{array}{l}\text { Kinematics } \\
\text { modeling of } \\
\text { five-axis machine } \\
\text { tool }\end{array}$ & Topic 60 & $\begin{array}{l}\text { Machine, five-axis, tool, coordinate, kinematics, kinematic, } \\
\text { transformation, axes, tools, matrix, simulation, location, function, } \\
\text { model, coordinates }\end{array}$ \\
\hline $\begin{array}{l}\text { Maintenance of } \\
\text { machine tool }\end{array}$ & Topic 61 & $\begin{array}{l}\text { Maintenance, source, cost, failure, replacement, policy, separation, } \\
\text { preventive, optimal, availability, independent, component, downtime, } \\
\text { repair, economic }\end{array}$ \\
\hline Neural network & Topic 62 & $\begin{array}{l}\text { Neural, network, artificial, ANN, data, training, input, prediction, } \\
\text { output, predict, algorithm, intelligence, parameters, multilayer, } \\
\text { back-propagation }\end{array}$ \\
\hline $\begin{array}{l}\text { Numerical control } \\
\text { system }\end{array}$ & Topic 63 & $\begin{array}{l}\mathrm{CNC} \text {, control, numerical, computer, controlled, numerically, machines, } \\
\text { lathe, computerized, aided, program, machine, numeric, } \\
\text { contribution, perform }\end{array}$ \\
\hline Tool path planning & Topic 64 & $\begin{array}{l}\text { Tool, cutter, surface, path, machining, orientation, five-axis, method, } \\
\text { contact, paths, orientations, point, location, positioning, generate }\end{array}$ \\
\hline Machine learning & Topic 65 & $\begin{array}{l}\text { Model, prediction, predict, regression, accuracy, modeling, data, } \\
\text { predictive, conditions, validation, accurately, linear, support, } \\
\text { correlation, LS-SVM }\end{array}$ \\
\hline $\begin{array}{l}\text { Micro electric } \\
\text { discharge } \\
\text { machining }\end{array}$ & Topic 66 & $\begin{array}{l}\text { Process, machining, micro-EDM, fabrication, electrochemical, high, } \\
\text { fabricated, ratio, effect, electrode, voltage, etching, microstructures, } \\
\text { capacitance, micro-electrical }\end{array}$ \\
\hline $\begin{array}{l}\text { Thermal error } \\
\text { compensation }\end{array}$ & Topic 67 & $\begin{array}{l}\text { Error, machine, accuracy, compensation, tool, induced, dimensional, } \\
\text { deviation, position, deviations, thermally, compensate, reduced, } \\
\text { adjustment, precision }\end{array}$ \\
\hline Adaptive control & Topic 68 & $\begin{array}{l}\text { Scheme, adaptive, performance, adaptation, transmission, improve, } \\
\text { predictor, efficiency, effectiveness, reliable, simulations, update, } \\
\text { simulation, enhance, adapt }\end{array}$ \\
\hline
\end{tabular}


Table A1. Cont.

\begin{tabular}{|c|c|c|}
\hline Meaning & Topic & High-Frequent Terms \\
\hline $\begin{array}{l}\text { Machining surface } \\
\text { roughness }\end{array}$ & Topic 69 & $\begin{array}{l}\text { Machining, surface, surfaces, blade, rough, tool, sculptured, five-axis, } \\
\text { method, blades, path, paths, convex, efficiency, tool-path }\end{array}$ \\
\hline Tool path planning & Topic 70 & $\begin{array}{l}\text { Path, tool, machining, offset, algorithm, generate, planning, curve, } \\
\text { method, boundary, spiral, points, offsetting, smooth, tool-path }\end{array}$ \\
\hline Welding machine & Topic 71 & $\begin{array}{l}\text { Welding, device, variable, mass, preload, automatic, weld, arc, high, } \\
\text { seam, metal, pressure, eccentric, gap, welded }\end{array}$ \\
\hline $\begin{array}{l}\text { Stamping } \\
\text { technology }\end{array}$ & Topic 72 & $\begin{array}{l}\text { Forming, process, metal, sheet, bending, thickness, cold, steel, tube, } \\
\text { flatness, punch, strain, stamping, punching, deformation }\end{array}$ \\
\hline Bearing & Topic 73 & $\begin{array}{l}\text { Bearing, bearings, ball, shaft, preload, contact, rotor, element, inner, } \\
\text { outer, angular, race, elements, rotating, roller }\end{array}$ \\
\hline $\begin{array}{l}\text { Measurement } \\
\text { technology }\end{array}$ & Topic 74 & $\begin{array}{l}\text { Measurement, laser, optical, device, displacement, technique, precision, } \\
\text { sensor, instrument, fiber, accuracy, positioning, tracker, calibration, } \\
\text { non-contact }\end{array}$ \\
\hline $\begin{array}{l}\text { Dynamic } \\
\text { characteristic } \\
\text { analysis }\end{array}$ & Topic 75 & $\begin{array}{l}\text { State, transient, continuous, dynamic, steady, dynamical, changes, } \\
\text { patterns, threshold, space, discrete, temporal, intervals, } \\
\text { stable, characterize }\end{array}$ \\
\hline $\begin{array}{l}\text { Dynamic modeling } \\
\text { of machine tool }\end{array}$ & Topic 76 & $\begin{array}{l}\text { Stability, dynamic, frequency, dynamics, response, modal, milling, } \\
\text { natural, damping, method, stable, modes, frequencies, } \\
\text { structural, stiffness }\end{array}$ \\
\hline $\begin{array}{l}\text { State evaluation of } \\
\text { machine tool }\end{array}$ & Topic 77 & $\begin{array}{l}\text { Test, data, indicator, lifetime, residual, technique, analysis, accelerated, } \\
\text { assess, deterioration, measure, rig, condition, criterion, validation }\end{array}$ \\
\hline $\begin{array}{l}\text { Forward transfer } \\
\quad \text { function }\end{array}$ & Topic 78 & $\begin{array}{l}\text { Function, transfer, approximation, case, method, coefficients, parameter, } \\
\text { complicated, efficiently, degree, forward, numerical, expression, } \\
\text { computing, polynomial }\end{array}$ \\
\hline Feature engineering & Topic 79 & $\begin{array}{l}\text { Feature, extraction, information, selection, classification, recognition, } \\
\text { method, reduction, domain, original, effectiveness, represent, } \\
\text { robustness, classify, preprocessing }\end{array}$ \\
\hline $\begin{array}{l}\text { Modeling theory of } \\
\text { machine tool }\end{array}$ & Topic 80 & $\begin{array}{l}\text { Model, modeling, models, accurate, mathematical, built, build, system, } \\
\text { theory, modeled, analyzing, principle, represent, cutterhead, damped }\end{array}$ \\
\hline Machining process & Topic 81 & $\begin{array}{l}\text { Milling, process, machining, cutting, processes, parameters, quality, } \\
\text { operations, cutter, operation, experiment, tests, slot, workpiece, } \\
\text { tool-workpiece }\end{array}$ \\
\hline $\begin{array}{l}\text { Conditions } \\
\text { monitoring }\end{array}$ & Topic 82 & $\begin{array}{l}\text { Signal, acoustic, signals, emission, analysis, sound, technique, } \\
\text { techniques, monitoring, processing, conditions, information, level, } \\
\text { recorded, estimation }\end{array}$ \\
\hline $\begin{array}{l}\text { Data sampling } \\
\text { method }\end{array}$ & Topic 83 & $\begin{array}{l}\text { Variable, variables, method, interval, correlation, sampling, points, } \\
\text { analysis, independent, selected, sample, data, distortion, } \\
\text { window, eliminate }\end{array}$ \\
\hline $\begin{array}{l}\text { Cooling and } \\
\text { lubrication system }\end{array}$ & Topic 84 & $\begin{array}{l}\text { Cooling, cutting, dry, fluid, machining, air, lubrication, minimum, } \\
\text { coolant, quantity, MQL, temperature, environment, liquid, lubricant }\end{array}$ \\
\hline $\begin{array}{l}\text { Linear interpolation } \\
\text { algorithm }\end{array}$ & Topic 85 & $\begin{array}{l}\text { Feedrate, acceleration, trajectory, algorithm, velocity, jerk, linear, } \\
\text { machining, smooth, profile, interpolation, planning, smoothing, } \\
\text { efficiency, path }\end{array}$ \\
\hline $\begin{array}{l}\text { Tool condition } \\
\text { monitoring }\end{array}$ & Topic 86 & $\begin{array}{l}\text { Tool, monitoring, condition, cutting, wear, on-line, signals, breakage, } \\
\text { system, process, detect, operations, online, reliable, real-time }\end{array}$ \\
\hline $\begin{array}{l}\text { Computer aided } \\
\text { design }\end{array}$ & Topic 87 & $\begin{array}{l}\text { Design, engineering, analysis, computer, prototype, designs, } \\
\text { manufacture, cad, synthesis, mechanical, computer-aided, evaluation, } \\
\text { redesign, built, requirements }\end{array}$ \\
\hline
\end{tabular}


Table A1. Cont.

\begin{tabular}{|c|c|c|}
\hline Meaning & Topic & High-Frequent Terms \\
\hline HMI & Topic 88 & $\begin{array}{l}\text { Software, system, module, interface, platform, hardware, modular, } \\
\text { electronic, interfaces, HMI, human, package, operating, post-processing, } \\
\text { human-machine }\end{array}$ \\
\hline Micro-milling & Topic 89 & $\begin{array}{l}\text { Micro, diameter, micro-milling, small, size, micromachining, miniature, } \\
\text { lapping, tools, precision, grooves, cylindrical, precise, mems, } \\
\text { miniaturization }\end{array}$ \\
\hline $\begin{array}{l}\text { Rotary axis } \\
\text { movement of } \\
\text { five-axis }\end{array}$ & Topic 90 & $\begin{array}{l}\text { Rotary, axis, machine, axes, angular, linear, head, position, rotational, } \\
\text { five-axis, tools, movement, orientation, rotation, multi-axis }\end{array}$ \\
\hline $\begin{array}{l}\text { Service } \\
\text { manufacturing }\end{array}$ & Topic 91 & $\begin{array}{l}\text { Product, design, products, quality, service, requirements, process, cycle, } \\
\text { customer, manufacturing, requirement, satisfy, association, } \\
\text { feasibility, model }\end{array}$ \\
\hline $\begin{array}{l}\text { Vibration } \\
\text { suppression }\end{array}$ & Topic 92 & $\begin{array}{l}\text { Vibration, ultrasonic, frequency, amplitude, mode, high, frequencies, } \\
\text { reduced, analyzed, reduction, resonance, forced, suppression, } \\
\text { excitation, self-excited }\end{array}$ \\
\hline $\begin{array}{l}\text { Remote control of } \\
\text { machine tool }\end{array}$ & Topic 93 & $\begin{array}{l}\text { Industrial, control, systems, communication, real-time, network, } \\
\text { automation, fieldbus, remote, networks, distributed, ethernet, } \\
\text { requirements, protocol, safety }\end{array}$ \\
\hline $\begin{array}{l}\text { Cutting force } \\
\text { measurement }\end{array}$ & Topic 94 & $\begin{array}{l}\text { Cutting, force, forces, measured, coefficients, conditions, process, } \\
\text { machining, feed, dynamometer, milling, resultant, mechanistic, } \\
\text { estimate, end-milling }\end{array}$ \\
\hline $\begin{array}{l}\text { Manipulator } \\
\text { kinematic analysis } \\
\text { of machine tool }\end{array}$ & Topic 95 & $\begin{array}{l}\text { Parallel, manipulator, kinematic, platform, freedom, kinematics, } \\
\text { degrees, DOF, hybrid, mechanism, dynamic, joint, space, } \\
\text { degree, analysis }\end{array}$ \\
\hline $\begin{array}{l}\text { Finite element } \\
\text { analysis }\end{array}$ & Topic 96 & $\begin{array}{l}\text { Element, finite, analysis, method, simulation, fem, numerical, model, } \\
\text { distribution, analyze, simulations, simulated, predict, modeling, } \\
\text { three-dimensional }\end{array}$ \\
\hline Gear fault diagnosis & Topic 97 & $\begin{array}{l}\text { Gear, fault, vibration, planetary, gearbox, frequency, signals, faults, } \\
\text { diagnosis, modulation, signal, planet, amplitude, components, analysis }\end{array}$ \\
\hline $\begin{array}{l}\text { Wire cutting } \\
\text { machining }\end{array}$ & Topic 98 & $\begin{array}{l}\text { Wire, machining, process, discharge, WEDM, pulse, parameters, } \\
\text { voltage, tension, gap, kerf, roughness, electrochemical, wire-EDM, } \\
\text { electro-discharge }\end{array}$ \\
\hline Motor & Topic 99 & $\begin{array}{l}\text { Motor, torque, mechanical, drive, linear, rotor, induction, synchronous, } \\
\text { system, driven, stator, currents, voltage, electromechanical, coupling }\end{array}$ \\
\hline $\begin{array}{l}\text { Adaptive tracking } \\
\text { and disturbance } \\
\text { rejection }\end{array}$ & Topic 100 & $\begin{array}{l}\text { Control, controller, tracking, system, disturbance, performance, } \\
\text { adaptive, nonlinear, disturbances, law, linear, mode, dynamics, } \\
\text { robustness, stability }\end{array}$ \\
\hline $\begin{array}{l}\text { Distributed } \\
\text { platform }\end{array}$ & Topic 101 & $\begin{array}{l}\text { Framework, information, integration, requirements, support, } \\
\text { distributed, platform, environment, execution, software, collaborative, } \\
\text { heterogeneous, prototype, interoperability, sharing }\end{array}$ \\
\hline $\begin{array}{l}\text { Multifunctional } \\
\text { machine tool }\end{array}$ & Topic 102 & $\begin{array}{l}\text { Systems, industrial, processes, components, tools, modern, industry, } \\
\text { complexity, domains, applicability, adapted, handling, suggest, } \\
\text { multifunctional, evolved }\end{array}$ \\
\hline $\begin{array}{l}\text { Prognostics and } \\
\text { health management } \\
\text { of machine tool }\end{array}$ & Topic 103 & $\begin{array}{l}\text { Monitoring, condition, health, machine, data, status, degradation, } \\
\text { diagnostic, machinery, maintenance, effective, assessment, prognostic, } \\
\text { information, collected }\end{array}$ \\
\hline Statistical method & Topic 104 & $\begin{array}{l}\text { Distribution, density, probability, stochastic, threshold, random, } \\
\text { statistical, gaussian, deterministic, value, function, distributions, } \\
\text { normal, assumption, likelihood }\end{array}$ \\
\hline
\end{tabular}


Table A1. Cont.

\begin{tabular}{|c|c|c|}
\hline Meaning & Topic & High-Frequent Terms \\
\hline $\begin{array}{l}\text { Hydraulic system } \\
\text { reliability }\end{array}$ & Topic 105 & $\begin{array}{l}\text { System, automatic, built, reliable, off-line, hydraulic, on-line, } \\
\text { enhancement, determines, reliability, details, adapt, automated, } \\
\text { specification, database }\end{array}$ \\
\hline $\begin{array}{l}\text { Machine tool } \\
\text { fixture }\end{array}$ & Topic 106 & $\begin{array}{l}\text { Workpiece, machining, setup, fixture, process, clamping, fixturing, case, } \\
\text { locating, layout, position, machined, holding, clamped, location }\end{array}$ \\
\hline $\begin{array}{l}\text { Spindle thermal } \\
\text { deformation }\end{array}$ & Topic 107 & $\begin{array}{l}\text { Thermal, temperature, heat, deformation, rise, modeling, transfer, } \\
\text { accuracy, spindle, robustness, field, points, expansion, regression, linear }\end{array}$ \\
\hline $\begin{array}{l}\text { Surface roughness } \\
\text { optimization }\end{array}$ & Topic 108 & $\begin{array}{l}\text { Surface, roughness, parameters, feed, cutting, rate, depth, values, } \\
\text { burnishing, quality, spindle, turning, average, predicted, optimum }\end{array}$ \\
\hline $\begin{array}{l}\text { Turbine blade } \\
\text { processing }\end{array}$ & Topic 109 & $\begin{array}{l}\text { Analysis, wind, turbine, method, dimension, nonlinear, kernel, } \\
\text { operation, sensitive, component, principal, linear, fractal, } \\
\text { turbines, components }\end{array}$ \\
\hline Damping design & Topic 110 & $\begin{array}{l}\text { Structure, machine, tool, damping, design, mechanical, hierarchical, } \\
\text { large, symmetrical, generalized, flexibility, capability, heavy-duty, } \\
\text { rigidity, theoretical }\end{array}$ \\
\hline Gear failure & Topic 111 & $\begin{array}{l}\text { Gear, tooth, crack, teeth, mesh, spur, transmission, damage, pitting, pair, } \\
\text { hobbing, helical, cracks, fatigue, failures }\end{array}$ \\
\hline Cnc & Topic 112 & $\begin{array}{l}\text { Control, system, feedback, active, loop, actuator, piezoelectric, dynamic, } \\
\text { real-time, subsystem, flexible, controlling, mechatronic, } \\
\text { closed-loop, hysteresis }\end{array}$ \\
\hline $\begin{array}{l}\text { Process parameter } \\
\text { optimization }\end{array}$ & Topic 113 & $\begin{array}{l}\text { Process, parameter, influence, values, combination, setting, optimum, } \\
\text { effect, analyzed, determining, optimal, suitable, measured, } \\
\text { appropriate, optimizing }\end{array}$ \\
\hline $\begin{array}{l}\text { Anti-collision } \\
\text { algorithm }\end{array}$ & Topic 114 & $\begin{array}{l}\text { Space, collision, interference, multi-axis, algorithms, area, detection, } \\
\text { simulation, avoidance, trajectory, collisions, efficient, accessibility, safe, } \\
\text { collision-free }\end{array}$ \\
\hline Gear fault diagnosis & Topic 115 & $\begin{array}{l}\text { Fault, diagnosis, vibration, faults, detection, gearbox, gear, signals, } \\
\text { machinery, condition, signal, rotating, diagnostic, monitoring, early }\end{array}$ \\
\hline $\begin{array}{l}\text { Metal-based } \\
\text { particle materials }\end{array}$ & Topic 116 & $\begin{array}{l}\text { Analysis, metal, principal, component, effective, hybrid, PCA, } \\
\text { multivariate, effect, particles, reinforced, properties, mechanical, } \\
\text { MMCS, machinability }\end{array}$ \\
\hline $\begin{array}{l}\text { Lubrication } \\
\text { technology }\end{array}$ & Topic 117 & $\begin{array}{l}\text { Oil, film, pressure, hydrostatic, lubrication, flow, bearing, gas, aerostatic, } \\
\text { lubricant, thickness, capacity, pump, performance, thrust }\end{array}$ \\
\hline $\begin{array}{l}\text { Kalman filter } \\
\text { method }\end{array}$ & Topic 118 & $\begin{array}{l}\text { Filter, loss, performance, filters, response, kalman, bandwidth, } \\
\text { frequency, impulse, waveguide, insertion, suitable, filtering, coupling, } \\
\text { low-pass }\end{array}$ \\
\hline Hob & Topic 119 & $\begin{array}{l}\text { Angle, rotation, tilt, model, pitch, degrees, helical, conical, inclination, } \\
\text { mathematical, analyzed, simulation, hob, profile, edge }\end{array}$ \\
\hline $\begin{array}{l}\text { Tool health } \\
\text { management }\end{array}$ & Topic 120 & $\begin{array}{l}\text { Wear, tool, measured, diffusion, influence, cutting, affects, tool-wear, } \\
\text { worn, severe, edges, crater, tool-life, predicting, estimate }\end{array}$ \\
\hline Error compensation & Topic 121 & $\begin{array}{l}\text { Error, compensation, accuracy, method, machine, precision, improve, } \\
\text { reduced, experiment, positioning, measurement, straightness, } \\
\text { volumetric, prediction, high-precision }\end{array}$ \\
\hline Machine learning & Topic 122 & $\begin{array}{l}\text { Classification, features, support, machine, classifier, SVM, conditions, } \\
\text { accuracy, extracted, data, recognition, feature, condition, } \\
\text { classifiers, statistical }\end{array}$ \\
\hline Big data & Topic 123 & $\begin{array}{l}\text { Data, information, acquisition, real-time, collect, amount, collection, } \\
\text { large, system, mining, huge, processed, management, database, } \\
\text { data-driven }\end{array}$ \\
\hline
\end{tabular}


Table A1. Cont.

\begin{tabular}{|c|c|c|}
\hline Meaning & Topic & High-Frequent Terms \\
\hline $\begin{array}{l}\text { Machine tool } \\
\text { flexibility }\end{array}$ & Topic 124 & $\begin{array}{l}\text { Manufacturing, processes, systems, industry, tools, production, modern, } \\
\text { automated, environment, integration, flexible, machine, global, } \\
\text { productivity, flexibility }\end{array}$ \\
\hline $\mathrm{CNC}$ & Topic 125 & $\begin{array}{l}\text { Program, CNC, programming, data, step-nc, iso, software, code, } \\
\text { language, systems, file, CADCAM, manufacturing, interface, } \\
\text { step-compliant }\end{array}$ \\
\hline $\begin{array}{l}\text { MT technology } \\
\text { forecasting }\end{array}$ & Topic 126 & $\begin{array}{l}\text { Future, industry, trends, techniques, field, analysis, developments, } \\
\text { purpose, understanding, findings, aspects, comprehensive, areas, } \\
\text { reviews, contribution }\end{array}$ \\
\hline Heuristic algorithm & Topic 127 & $\begin{array}{l}\text { Problem, solve, solution, optimal, heuristic, algorithm, programming, } \\
\text { processing, search, minimize, sequence, formulated, machines, } \\
\text { computational, parallel }\end{array}$ \\
\hline Open CNC system & Topic 128 & $\begin{array}{l}\text { System, CNC, architecture, control, open, real-time, controller, software, } \\
\text { computer, numerical, embedded, kernel, pc-based, remote, intelligent }\end{array}$ \\
\hline $\begin{array}{l}\text { Part surface defect } \\
\text { detection }\end{array}$ & Topic 129 & $\begin{array}{l}\text { Detection, defect, detect, damage, analysis, test, localized, processing, } \\
\text { case, early, on-line, location, anomalies, identifying, serious }\end{array}$ \\
\hline $\begin{array}{l}\text { Ultrahigh-speed } \\
\text { machining }\end{array}$ & Topic 130 & $\begin{array}{l}\text { Machining, process, quality, productivity, efficient, work-piece, } \\
\text { parameters, cost, essential, conditions, ultrahigh-speed, multi-tool, } \\
\text { economics, powerful, high-efficiency }\end{array}$ \\
\hline $\begin{array}{l}\text { Machine tool } \\
\text { condition } \\
\text { monitoring }\end{array}$ & Topic 131 & $\begin{array}{l}\text { Process, quality, control, manufacturing, chart, monitoring, statistical, } \\
\text { variables, improvement, product, monitor, improve, productivity, } \\
\text { adaptive, actions }\end{array}$ \\
\hline Image recognition & Topic 132 & $\begin{array}{l}\text { Image, vision, object, processing, spatial, visual, camera, recognition, } \\
\text { area, digital, automatic, tracking, video, three-dimensional, vision-based }\end{array}$ \\
\hline Structure design & Topic 133 & $\begin{array}{l}\text { Component, structural, structure, design, mechanical, performance, } \\
\text { topology, essential, weight, interaction, case, aspects, reasonable, } \\
\text { inherent, topologies }\end{array}$ \\
\hline Cutting tool wear & Topic 134 & $\begin{array}{l}\text { Cutting, tool, tools, carbide, wear, steel, machining, materials, coated, } \\
\text { hard, inserts, turning, conditions, INCONEL, machinability }\end{array}$ \\
\hline Expert system & Topic 135 & $\begin{array}{l}\text { Knowledge, system, expert, process, information, base, database, } \\
\text { engineering, reasoning, case, rules, experience, human, data, } \\
\text { knowledge-based }\end{array}$ \\
\hline CNC system & Topic 136 & $\begin{array}{l}\text { Digital, unit, system, hardware, processing, processor, field, } \\
\text { programmable, signal, FPGA, array, gate, structure, PLC, DSP }\end{array}$ \\
\hline $\begin{array}{l}\text { Machine tool } \\
\text { kinematics } \\
\text { modeling }\end{array}$ & Topic 137 & $\begin{array}{l}\text { Motion, direction, circular, axis, method, vertical, tests, trajectory, linear, } \\
\text { planar, rotational, double, three-axis, longitudinal, horizontal }\end{array}$ \\
\hline $\begin{array}{l}\text { Efficiency } \\
\text { improvement }\end{array}$ & Topic 138 & $\begin{array}{l}\text { Efficiency, processing, high, quality, improve, improved, increase, } \\
\text { amount, enhance, feasibility, analyzing, situation, plane, } \\
\text { maintaining, superiority }\end{array}$ \\
\hline Deep learning & Topic 139 & $\begin{array}{l}\text { Learning, deep, algorithms, cluster, representations, online, framework, } \\
\text { datasets, clusters, supervised, unsupervised, dataset, classification, } \\
\text { convolutional, temporal }\end{array}$ \\
\hline $\begin{array}{l}\text { Surface 3D } \\
\text { reconstruction }\end{array}$ & Topic 140 & $\begin{array}{l}\text { Surface, point, free-form, method, mesh, sampling, engineering, } \\
\text { reconstruction, reverse, cad, distance, shape, subdivision, } \\
\text { three-dimensional, boundary }\end{array}$ \\
\hline Grinding process & Topic 141 & $\begin{array}{l}\text { Grinding, wheel, process, workpiece, ground, surface, machine, } \\
\text { diamond, grinder, profile, belt, cylindrical, efficiency, abrasive, } \\
\text { micro-grinding }\end{array}$ \\
\hline
\end{tabular}


Table A1. Cont.

\begin{tabular}{|c|c|c|}
\hline Meaning & Topic & High-Frequent Terms \\
\hline $\begin{array}{l}\text { Virtual reality and } \\
\text { augmented reality }\end{array}$ & Topic 142 & $\begin{array}{l}\text { Virtual, reality, environment, augmented, industrial, task, training, } \\
\text { interaction, display, visualization, cognitive, scenario, interface, } \\
\text { operator, intuitive }\end{array}$ \\
\hline $\begin{array}{l}\text { High speed and } \\
\text { high precision } \\
\text { machine tool }\end{array}$ & Topic 143 & $\begin{array}{l}\text { High, accuracy, precision, improve, dimensional, higher, productivity, } \\
\text { high-precision, resolution, parts, requirements, performance, } \\
\text { machining, cost-effective, high-quality }\end{array}$ \\
\hline $\begin{array}{l}\text { Laser } \\
\text { interferometer }\end{array}$ & Topic 144 & $\begin{array}{l}\text { Laser, beam, zone, scanning, quality, continuous, taper, interferometer, } \\
\text { width, CNC, power, direction, materials, laser-assisted, heat-affected }\end{array}$ \\
\hline $\begin{array}{l}\text { Electric discharge } \\
\text { machining }\end{array}$ & Topic 145 & $\begin{array}{l}\text { Discharge, EDM, machining, pulse, electrical, process, gap, plasma, } \\
\text { duration, voltage, workpiece, crater, spark, arc, dielectric }\end{array}$ \\
\hline Cutting process & Topic 146 & $\begin{array}{l}\text { Cutting, depth, cut, radial, axial, milling, feed, width, high-speed, } \\
\text { process, machining, maximum, groove, tangential, immersion }\end{array}$ \\
\hline Residual stress & Topic 147 & $\begin{array}{l}\text { Stress, residual, fatigue, material, alloy, strength, stresses, titanium, } \\
\text { high, properties, resistance, mechanical, aluminum, materials, effect }\end{array}$ \\
\hline $\begin{array}{l}\text { Lathe machining } \\
\text { process }\end{array}$ & Topic 148 & $\begin{array}{l}\text { Turning, tool, cutting, lathe, machining, process, workpiece, machine, } \\
\text { operation, ultra-precision, cylindrical, roundness, diamond, } \\
\text { turned, flycutting }\end{array}$ \\
\hline Drilling & Topic 149 & $\begin{array}{l}\text { Drilling, hole, drill, holes, thrust, process, diameter, force, burr, feed, } \\
\text { deep, drills, spindle, quality, steel }\end{array}$ \\
\hline $\begin{array}{l}\text { Digital modeling of } \\
\text { machine tool }\end{array}$ & Topic 150 & $\begin{array}{l}\text { Simulation, model, numerical, mathematical, modelling, dynamic, } \\
\text { verification, simulate, purpose, simplified, MATLAB, simulator, } \\
\text { software, finite-element, comprehensive }\end{array}$ \\
\hline $\begin{array}{l}\text { Contour error } \\
\text { control }\end{array}$ & Topic 151 & $\begin{array}{l}\text { Contour, error, tracking, control, controller, trajectory, motion, position, } \\
\text { accuracy, axis, CNC, multi-axis, desired, cross-coupled, reduced }\end{array}$ \\
\hline Tool path planning & Topic 152 & $\begin{array}{l}\text { Machining, toolpath, corner, high-speed, length, sharp, toolpaths, } \\
\text { corners, curvature, HSM, height, continuous, path, zones, lengths }\end{array}$ \\
\hline $\begin{array}{l}\text { Cloud computing } \\
\text { and Cyber-physical } \\
\text { system }\end{array}$ & Topic 153 & $\begin{array}{l}\text { Cloud, computing, service, internet, architecture, devices, physical, fog, } \\
\text { resources, things, industrial, platform, iot, cyber-physical, cyber }\end{array}$ \\
\hline $\begin{array}{l}\text { Machine tool } \\
\text { fixture }\end{array}$ & Topic 154 & $\begin{array}{l}\text { Tool, machine, holder, tools, tests, equipped, productivity, part, } \\
\text { simplified, avoiding, incorporate, amplification, tool-setting, } \\
\text { test, installed }\end{array}$ \\
\hline $\begin{array}{l}\text { Reconfigurable } \\
\text { machine tool }\end{array}$ & Topic 155 & $\begin{array}{l}\text { Configuration, design, machine, reconfigurable, systems, requirements, } \\
\text { manufacturing, changes, flexible, flexibility, machines, reconfiguration, } \\
\text { modular, rapid, scalability }\end{array}$ \\
\hline $\begin{array}{l}\text { Efficiency } \\
\text { improvement }\end{array}$ & Topic 156 & $\begin{array}{l}\text { Method, effectiveness, accuracy, efficiency, efficient, characteristic, } \\
\text { improve, combines, experiment, suitable, efficiently, acquire, first-order, } \\
\text { off-line, repeated }\end{array}$ \\
\hline Machining process & Topic 157 & $\begin{array}{l}\text { Milling, cutting, tool, cutter, deflection, edge, workpiece, mill, ball-end, } \\
\text { forces, engagement, angle, surface, direction, ball }\end{array}$ \\
\hline $\begin{array}{l}\text { Hidden markov } \\
\text { model }\end{array}$ & Topic 158 & $\begin{array}{l}\text { Estimation, model, state, method, markov, hidden, prediction, accurate, } \\
\text { remaining, parameters, estimator, online, bayesian, algorithm, HMM }\end{array}$ \\
\hline
\end{tabular}




\section{Appendix B}

Table A2. The coverage rates of four experiments.

\begin{tabular}{ccc}
\hline Experiment & Number of Topics Remodeled & Recurrence Ratio \\
\hline Experiment 1 & 130 & 0.82278481 \\
Experiment 2 & 132 & 0.83544304 \\
Experiment 3 & 128 & 0.81012658 \\
experiment 4 & 127 & 0.80379747 \\
\hline
\end{tabular}

\section{References}

1. Ji, Z.; Li, P.; Zhou, Y.; Wang, B.; Zang, J.; Liu, M. Toward New-Generation Intelligent Manufacturing. Engineering 2018, 4, 11-20.

2. Kang, H.S.; Lee, J.Y.; Choi, S.; Kim, H.; Park, J.H.; Son, J.Y.; Kim, B.H.; Noh, S.D. Smart Manufacturing: Past Research, Present Findings, and Future Directions. Int. J. Precis. Eng. Manuf. Green Technol. 2016, 3, 111-128. [CrossRef]

3. Tao, F.; Qi, Q.L.; Liu, A.; Kusiak, A. Data-driven smart manufacturing. J. Manuf. Syst. 2018, 48, 157-169. [CrossRef]

4. Liu, C.; Vengayil, H.; Zhong, R.Y.; Xu, X. A systematic development method for cyber-physical machine tools. J. Manuf. Syst. 2018, 48, 13-24. [CrossRef]

5. Liu, C.; Xu, X. Cyber-Physical Machine Tool-The Era of Machine Tool 4.0. Proc. Cirp. 2017, 63, 70-75. [CrossRef]

6. Zaeh, M.; Graetz, F.; Rashidy, H. An Approach to Simultaneous Development in Machine Tool Industry. In Proceedings of the 2003 Conference on the Modelling \& Applied Simulation, Bergeggi, Italy, 2-4 October 2003; pp. 128-133.

7. Xu, X. Machine Tool 4.0 for the new era of manufacturing. Int. J. Adv. Manuf. Technol. 2017, 92, $1893-1900$. [CrossRef]

8. Raju, L.; Hiremath, S.S. A State-of-the-art Review on Micro Electro-Discharge Machining. Proc. Technol. 2016, 25, 1281-1288. [CrossRef]

9. Zhou, L.R.; Li, J.F.; Li, F.Y.; Meng, Q.; Li, J.; Xu, X.S. Energy consumption model and energy efficiency of machine tools: A comprehensive literature review. J. Clean. Prod. 2016, 112, 3721-3734. [CrossRef]

10. Lenz, J.; Wuest, T.; Westkamper, E. Holistic approach to machine tool data analytics. J. Manuf. Syst. 2018, 48, 180-191. [CrossRef]

11. Yang, H.L.; Chang, T.W.; Choi, Y. Exploring the Research Trend of Smart Factory with Topic Modeling. Sustainability 2018, 10, 2779. [CrossRef]

12. Tichy, G. The over-optimism among experts in assessment and foresight. Technol. Forecast. Soc. 2004, 71, 341-363. [CrossRef]

13. Liu, H.Y.; Yu, J.N.; Xu, J.; Fan, Y.; Bao, X.J. Identification of key oil refining technologies for China National Petroleum Co. (CNPC). Energy Policy 2007, 35, 2635-2647. [CrossRef]

14. Jiang, H.C.; Qiang, M.S.; Lin, P. Finding academic concerns of the Three Gorges Project based on a topic modeling approach. Ecol. Indic. 2016, 60, 693-701. [CrossRef]

15. Sun, L.J.; Yin, Y.F. Discovering themes and trends in transportation research using topic modeling. Transport. Res. C Emerg. Technol. 2017, 77, 49-66. [CrossRef]

16. Marzi, G.; Dabic, M.; Daim, T.; Garces, E. Product and process innovation in manufacturing firms: A 30-year bibliometric analysis. Scientometrics 2017, 113, 673-704. [CrossRef]

17. Yu, D.J.; Xu, Z.S.; Fujita, H. Bibliometric analysis on the evolution of applied intelligence. Appl. Intell. 2019, 49, 449-462. [CrossRef]

18. Zhou, Y.; Pan, M.J.; Urban, F. Comparing the International Knowledge Flow of China's Wind and Solar Photovoltaic (PV) Industries: Patent Analysis and Implications for Sustainable Development. Sustainability 2018, 10, 1883. [CrossRef]

19. Wang, Y.W.; Urban, F.; Zhou, Y.; Chen, L.Y. Comparing the Technology Trajectories of Solar PV and Solar Water Heaters in China: Using a Patent Lens. Sustainability 2018, 10, 11. [CrossRef] 
20. Nordensvard, J.; Yuan, Z.; Xiao, Z. Innovation core, innovation semi-periphery and technology transfer: The case of wind energy patents. Energy Policy 2018, 120, 213-227. [CrossRef]

21. Ernst, H. The use of patent data for technological forecasting: The diffusion of CNC-technology in the machine tool industry. Small Bus. Econ. 1997, 9, 361-381. [CrossRef]

22. Yeo, W.; Kim, S.; Park, H.; Kang, J. A bibliometric method for measuring the degree of technological innovation. Technol. Forecast. Soc. Chang. 2015, 95, 152-162. [CrossRef]

23. Jun, S. A Forecasting Model for Technological Trend Using Unsupervised Learning. In Database Theory and Application, Bio-Science and Bio-Technology; Springer: Berlin/Heidelberg, Germany, 2011; Volume 258, pp. 51-60.

24. Kulkarni, S.S.; Apte, U.M.; Evangelopoulos, N.E. The Use of Latent Semantic Analysis in Operations Management Research. Decis. Sci. 2014, 45, 971-994. [CrossRef]

25. Wang, B.C.; Liu, Y.F.; Zhou, Y.; Wen, Z. Emerging nanogenerator technology in China: A review and forecast using integrating bibliometrics, patent analysis and technology roadmapping methods. Nano Energy 2018, 46, 322-330. [CrossRef]

26. Suominen, A.; Peng, H.; Ranaei, S. Examining the dynamics of an emerging research network using the case of triboelectric nanogenerators. Technol. Forecast. Soc. 2018. [CrossRef]

27. Blei, D.M.; Ng, A.Y.; Jordan, M.I. Latent dirichlet allocation. J. Mach. Learn. Res. 2003, 3, 993-1022.

28. Griffiths, T.L.; Steyvers, M. Finding scientific topics. Proc. Natl. Acad. Sci. USA 2004, 101, 5228-5235. [CrossRef]

29. Jiang, H.C.; Qiang, M.S.; Lin, P. A topic modeling based bibliometric exploration of hydropower research. Renew. Sustain. Energy Rev. 2016, 57, 226-237. [CrossRef]

30. Zhang, Y.; Chen, H.S.; Lu, J.; Zhang, G.Q. Detecting and predicting the topic change of Knowledge-based Systems: A topic-based bibliometric analysis from 1991 to 2016. Knowl. Based Syst. 2017, 133, 255-268. [CrossRef]

31. Choi, H.S.; Lee, W.S.; Sohn, S.Y. Analyzing research trends in personal information privacy using topic modeling. Comput. Secur. 2017, 67, 244-253. [CrossRef]

32. Abuhay, T.M.; Kovalchuk, S.V.; Bochenina, K.; Mbogo, G.K.; Visheratin, A.A.; Kampis, G.; Krzhizhanovskaya, V.V.; Lees, M.H. Analysis of publication activity of computational science society in 2001-2017 using topic modelling and graph theory. J. Comput. Sci. 2018, 26, 193-204. [CrossRef]

33. Kim, M.; Gupta, B.B.; Rho, S. Crowdsourcing based scientific issue tracking with topic analysis. Appl. Soft Comput. 2018, 66, 506-511. [CrossRef]

34. Tang, D. Algorithms for collision detection and avoidance for five-axis NC machining: A state of the art review. Comput. Aided Des. 2014, 51,1-17. [CrossRef]

35. Lauro, C.H.; Brandao, L.C.; Baldo, D.; Reis, R.A.; Davim, J.P. Monitoring and processing signal applied in machining processes-A review. Measurement 2014, 58, 73-86. [CrossRef]

36. Cao, H.R.; Zhang, X.W.; Chen, X.F. The concept and progress of intelligent spindles: A review. Int. J. Mach. Tools Manuf. 2017, 112, 21-52. [CrossRef]

37. Li, Y.; Zhao, W.H.; Lan, S.H.; Ni, J.; Wu, W.W.; Lu, B.H. A review on spindle thermal error compensation in machine tools. Int. J. Mach. Tools Manuf. 2015, 95, 20-38. [CrossRef]

38. He, X.C. Recent development in reliability analysis of NC machine tools. Int. J. Adv. Manuf. Technol. 2016, 85, 115-131. [CrossRef]

39. Gadalla, M.; Xue, D.Y. Recent advances in research on reconfigurable machine tools: A literature review. Int. J. Prod. Res. 2017, 55, 1440-1454. [CrossRef]

40. Liu, C.; Xu, X.; Peng, Q.; Zhou, Z. MTConnect-based Cyber-Physical Machine Tool: A case study. Procedia CIRP 2018, 72, 492-497. [CrossRef]

41. Mao, G.Z.; Huang, N.; Chen, L.; Wang, H.M. Research on biomass energy and environment from the past to the future: A bibliometric analysis. Sci. Total Environ. 2018, 635, 1081-1090. [CrossRef] [PubMed]

42. Kong, D.; Yuan, Z.; Liu, Y.; Lan, X. Using the data mining method to assess the innovation gap: A case of industrial robotics in a catching-up country. Technol. Forecast. Soc. Chang. 2017, 119, 80-97. [CrossRef]

43. Xu, G.N.; Wu, Y.C.; Minshall, T.; Zhou, Y. Exploring innovation ecosystems across science, technology, and business: A case of 3D printing in China. Technol. Forecast. Soc. 2018, 136, 208-221. [CrossRef]

44. Nichols, L.G. A topic model approach to measuring interdisciplinarity at the National Science Foundation. Scientometrics 2014, 100, 741-754. [CrossRef] 
45. Li, X.; Xie, Q.; Jiang, J.; Zhou, Y.; Huang, L. Identifying and monitoring the development trends of emerging technologies using patent analysis and Twitter data mining: The case of perovskite solar cell technology. Technol. Forecast. Soc. 2018. [CrossRef]

46. Verkruijsse, L. How to predict the development of breakthrough technologies with the help of electronic databases? In Technology, Strategy and Entrepreneurship; TU Delft: Delft, The Netherlands, 2010; Volume 131.

47. Mann, H.B. Nonparametric tests against trend. Econom. J. Econom. Soc. 1945, 13, 245-259. [CrossRef]

48. Liu, J.S.; Kuan, C.H.; Cha, S.C.; Chuang, W.L.; Gau, G.J.; Jeng, J.Y. Photovoltaic technology development: A perspective from patent growth analysis. Sol. Energy Mater. Sol. Cells 2011, 95, 3130-3136. [CrossRef]

49. Yao, Q.; Chen, K.; Yao, L.; Lyu, P.H.; Yang, T.A.; Luo, F.; Chen, S.Q.; He, L.Y.; Liu, Z.Y. Scientometric trends and knowledge maps of global health systems research. Health Res. Policy Syst. 2014, 12, 26. [CrossRef] [PubMed]

50. Chang, J.; Gerrish, S.; Wang, C.; Boyd-Graber, J.L.; Blei, D.M. Reading tea leaves: How humans interpret topic models. In Advances in Neural Information Processing Systems; Advances in Neural Information Processing Systems: Vancouver, BC, Canada, 2009; pp. 288-296.

51. Mimno, D.; Wallach, H.M.; Talley, E.; Leenders, M.; McCallum, A. Optimizing semantic coherence in topic models. In Proceedings of the Conference on Empirical Methods in Natural Language Processing, Edinburgh, UK, 27-31 July 2011; Association for Computational Linguistics: Stroudsburg, PA, USA, 2011; pp. $262-272$.

52. Chen, Z.; Liu, B. Topic modeling using topics from many domains, lifelong learning and big data. In Proceedings of the International Conference on Machine Learning, Beijing, China, 21-26 June 2014; pp. 703-711.

(C) 2019 by the authors. Licensee MDPI, Basel, Switzerland. This article is an open access article distributed under the terms and conditions of the Creative Commons Attribution (CC BY) license (http://creativecommons.org/licenses/by/4.0/). 